This item was submitted to Loughborough's Research Repository by the author.

Items in Figshare are protected by copyright, with all rights reserved, unless otherwise indicated.

\title{
Effect of visible light and electrode wetting on the capacitive performance of S- and N-doped nanoporous carbons: Importance of surface chemistry
}

\section{PLEASE CITE THE PUBLISHED VERSION}

http://dx.doi.org/10.1016/j.carbon.2014.07.038

\section{PUBLISHER}

(C) Elsevier

VERSION

AM (Accepted Manuscript)

\section{PUBLISHER STATEMENT}

This work is made available according to the conditions of the Creative Commons Attribution-NonCommercialNoDerivatives 4.0 International (CC BY-NC-ND 4.0) licence. Full details of this licence are available at: https://creativecommons.org/licenses/by-nc-nd/4.0/

\section{LICENCE}

CC BY-NC-ND 4.0

\section{REPOSITORY RECORD}

Seredych, Mykola, Enrique Rodriguez-Castellon, Mark J. Biggs, William Skinner, and Teresa J. Bandosz. 2019. "Effect of Visible Light and Electrode Wetting on the Capacitive Performance of S- and N-doped Nanoporous Carbons: Importance of Surface Chemistry”. figshare. https://hdl.handle.net/2134/25135. 


\section{Effect of visible light and electrode wetting on the capacitive performance of S- and $\mathrm{N}$-doped nanoporous carbons: Importance of surface chemistry}

Mykola Seredych ${ }^{1}$, Enrique Rodríguez-Castellón ${ }^{2}$, Mark J. Biggs ${ }^{3}$, William Skinner ${ }^{4}$ and Teresa J. Bandosz $z^{1 *}$

${ }^{1}$ Department of Chemistry, The City College of New York,160 Convent Ave, New York, NY, 10031, USA.

${ }^{2}$ Departamento de Química Inorgánica, Universidad de Málaga, Spain.

${ }^{3}$ School of Chemical Engineering, The University of Adelaide, Adelaide, SA 5005, Australia.

${ }^{4}$ Ian Wark Research Institute, The ARC Special Research Centre for Particle and Material Interfaces, University of South Australia, Mawson Lakes, Adelaide, SA 5095, Australia.

*Corresponding author. Tel: (212) 650-6017; Fax: (212) 650-6107; E-mail address: tbandosz@ccny.cuny.edu (T.J. Bandosz) 


\begin{abstract}
Nanoporous carbons with graphitic domains were synthesized from a polymer containing sulfur and nitrogen. The materials were characterized using adsorption of nitrogen, potentiometric titration TA/MS, XPS, TEM and XRD. Then they were tested as supercapacitors in threeelectrode cell and under visible light irradiation after extensive wetting either in water or a sulfuric acid electrolyte. The capacitance up to $450 \mathrm{~F} / \mathrm{g}$ was measured in spite of a relatively low surface $\left(<850 \mathrm{~m}^{2} / \mathrm{g}\right)$. The surface chemistry, and especially sulfur and nitrogen containing functional groups, were found of paramount importance for the capacitive behavior and for the effective pore space utilization by the electrolyte ions. Photocurrent measured in light also affects the capacitance. Its generation is linked to the excitation of sulfonic/sulfoxide chromophores-like moieties decorating the surface of the polymer-derived carbons.
\end{abstract}




\section{Introduction}

A need to develop new, nonconventional sources of energy driven by environmental sustainability has led to an extensive research on the development of new materials being able to efficiently store energy. Efficiently here means with a high gravimetric and volumetric capacitances and with high energy and power densities. During the last decade numerous original research papers and reviews have been published analyzing the factor governing these features [1-10]. Generally two types of materials have been considered: carbon based supercapacitors [18] and metal oxides based redox type capacitors [10, 11]. To increase the performance the composites of both types of materials have been also considered [9-12].

In the case of carbon-based supercapacitors electrical double layer of ions on the surface has been identified as the main mechanism of charge storage [6, 13-17]. The advantage of these materials is in their high porosity and therefore in a developed surface area promoting electrical double layer capacitance (EDLC). It has been demonstrated that for charge storage the pores similar to sizes of electrolyte ions, generally smaller than $0.7 \mathrm{~nm}$, are of paramount importance $[13-15,17]$ EDLC is also affected by the wettability of the carbon [17-20], its conductivity [17, 19, 20], and other electric properties of carbons such as surface charge delocalization [7, 14]. All of these affect the utilization of the pore space for EDL of ions and thus the efficiency of a charge storage. It has been demonstrated that the electrochemical capacitance can be high for the carbon with a relatively low volume of pores smaller than $0.7 \mathrm{~nm}$ owing to the right combination of important surface features [17, 20]. 
Another aspect of the capacitive performance of carbon-based materials is the pseudocapacitance originated from Faradaic reactions on the functional groups located in the pore system. Those groups consist of heteroatoms incorporated to a carbon matrix at various configurations. So far the main attention of the researchers has been focused on oxygen and nitrogen functionalities and specifically quinone/hydroquinone [16], pyrrole and pyridinic nitrogen [21, 22]. Quaternary-N and pyridinic-N-oxide were shown as affecting an electron transfer through the carbon matrix [22] and phosphorous groups were found as increasing the stability of supercapacitors at high operation voltage in acidic electrolytes [23]. All these groups, owing to their geometry, rather exist in pores larger than $1 \mathrm{~nm}$, therefore larger micropores and mesopores, besides being transport channels for an ion transfer, also actively participate in a capacitive performance.

Recently, the importance of sulfur containing groups such as sulfones and sulfoxides for pseudocapacitance has been pointed out [3, 8, 24, 25]. Moreover, on sulfur doped carbon, sulfur can be present in aromatic rings of the graphene layers and thus in pore walls as their defective sites affecting the charge on the carbon atoms and attracting more ions via EDLC [8, 25-27].

Those mentioned above properties of heteroatoms led to an investigation of S- and $\mathrm{N}$ - doped carbons as supercapacitors. So far studies of these chemically heterogeneous materials have been in the initial stages and such factors as change in the charge density profiles due to different electronegativities of sulfur and nitrogen atoms than carbon [26], changes in polarizability [26], redox reactions of sulfones and sulfoxides $[8,24,25]$ and photoactivity of sulfur functionalities [28] were indicated as affecting the charge storage mechanism on these materials. As the objective of this paper we have chosen to investigate three important aspects of a supercapacitor performance. The first aspect focuses on studying the effect of the S- and N- containing groups 
incorporated to the carbon surface on the capacitive performance. Here, based on the fact that Sdoped reduced graphite oxides or carbons have been found to be promoting oxygen reduction reactions [26, 27, 29], we focus the investigation on identifying the contribution of these groups for visible light (VL) induced Faradaic reactions, which might increase the overall capacitive performance. The investigation of this visible light effect is the second objective of this research. The third stream of our study addresses an aspect of extensive wetting in an electrolyte and the changes it can bring to the carbon surface. Even though the importance of wetting for pore accessibility has been pointed out $[17,20]$, the changes to the carbon caused by this process have not been taken into consideration.

\section{Experimental}

\subsection{Materials}

Two independent sets of carbons were studied. The first set are based on a carbon, denoted henceforth by C-A, that was derived from carbonization of Poly(4-ammonium styrene-sulfonic acid) in nitrogen at $800{ }^{\circ} \mathrm{C}$ for $40 \mathrm{~min}\left(\mathrm{~N}_{2}\right.$ flow rate of $300 \mathrm{~mL} / \mathrm{min}$ and heating rate of 50

${ }^{\circ} \mathrm{C} / \mathrm{min}$ ). The second set are based on a carbon obtained from carbonization under the same conditions as C-A of a 1:1 mixture of 30\% solution of Poly(4-ammonium styrene-sulfonic acid) and Poly(4-styrenesulfonic acid-co-maleic acid) sodium salt, denoted as C-B. Oxidized versions of these two carbons, denoted as $\mathrm{C}-\mathrm{AO}$ and $\mathrm{C}-\mathrm{BO}$, were obtained by heating them in air at 350 ${ }^{\circ} \mathrm{C}$ for 3 hours.

\subsection{Methods}


2.2.1. Electrochemical measurements: Prior to electrochemical measurements in order to avoid polarization of the working electrode, the electrodes were wet in distilled water or in sulfuric acid (1 M) for 72 hours. Then the open circuit potential (OCP) vs. Ag/AgCl was recorded in $1 \mathrm{M}$ $\mathrm{H}_{2} \mathrm{SO}_{4}$. The constant value indicated the wetting of the entire surface. Then the cyclic voltammetry $(\mathrm{CV})$ were run in a very narrow potential window (from $0.2 \mathrm{~V}$ to $-0.2 \mathrm{~V}$ ) to confirm a lack of changes in $\mathrm{CV}$ with an increase in the number of cycles (an example of OCP and CV are presented on Figure S1 of Supplementary Information). Photoelectrochemical measurements were carried out in $1 \mathrm{M} \mathrm{H}_{2} \mathrm{SO}_{4}$ in a three-electrode cell, a Pt wire counter electrode, and a saturated $\mathrm{Ag} / \mathrm{AgCl}(3 \mathrm{M} \mathrm{KCl})$ reference electrode. For the preparation of the electrode a slurry of the non-oxidized or air oxidized carbon, polyvinylidene fluoride (PVDF) and a carbon black conductive additive (ratio 80:10:10) in N-methyl-2-pyrrolidone (NMP) was coated on a Ti foil collector with an active area of $1 \mathrm{~cm}^{2}$. The electrodes were dried in air at $120{ }^{\circ} \mathrm{C}$. A solar simulator (Solar Light Co., INC, XPS-150TM) with a $420 \mathrm{~nm}$ cut-off filter was used as irradiation source. A VersaSTAT MC (Princeton Applied Research) electrochemical workstation was employed for recording the electrochemical behavior. The transient of photocurrent was obtained under a constant bias potential between 0.6 and $-0.2 \mathrm{~V}$ vs. Ag/AgCl under on/off illumination. Dark current equilibrium at the applied potential was allowed before the irradiation. The values of the specific capacitance (F/g) were estimated by cyclic voltammetry (scan rate of potential $5 \mathrm{mV} / \mathrm{s}$ ). The specific capacitance was calculated according to the Equation:

$$
\mathrm{C}=\mathrm{Q} /\left(\Delta \mathrm{E}^{*} \mathrm{~m}\right)
$$

where $Q$ is the charge obtained after integrating the voltammogram, $m$ is the total mass of electrode, and $\Delta E$ is the potential window. 
The materials consisting of built electrodes (active material + PVDF + carbon black) have E added to their names. After CV and chronoamperometry run under on/off illumination in three electrode cell they are referred to with the letter U. The initial carbon materials after wetting in sulfuric acid (1 M) are referred to with suffix " $\mathrm{H}_{2} \mathrm{SO}_{4}$ ” .

2.2.2. Surface characterization: Sorption of nitrogen at $-196{ }^{\circ} \mathrm{C}$ was carried out using an ASAP 2020 (Micromeritics, Surface Area and Porosity Analyzer) on the active materials/carbons. Before the experiments, samples were out-gassed at $120{ }^{\circ} \mathrm{C}$ to constant vacuum $\left(10^{-4} \mathrm{Torr}\right)$. The surface areas (BET method), total pore volumes, $V_{t}$, (from the last point of isotherm at relative pressure equal to 0.99), volumes of micropores, volume of pores less than $0.7 \mathrm{~nm}$ and $1 \mathrm{~nm}$, $\mathrm{V}_{<0.7 \mathrm{~nm}}$ and $\mathrm{V}_{<1 \mathrm{~nm}}$, mesopore volumes along with pore size distributions were calculated from the isotherms. The last four quantities were calculated using Density Functional Theory, DFT [30]. 2.2.3. $X$-ray diffraction (XRD): XRD measurements were conducted on the active carbon components of the electrodes using standard powder diffraction procedures analyzed by $\mathrm{Cu}_{\mathrm{K} \alpha}$ radiation (40 kV and $40 \mathrm{~mA}$ ) generated in a Phillips X'Pert X-ray diffractometer. The scan rate used was $2.3 \mathrm{deg} / \mathrm{min}$.

2.2.4. Raman spectroscopy: Raman spectra were collected on a Princeton Instruments Acton 2750 SpectroPro $0.750 \mathrm{~m}$ Triple Grating Monochromator fitted with an Olympus BX-51 microscope and $100 \times$ objective using a 514.5 nm Argon-ion laser with a $1200 \mathrm{gr} / \mathrm{mm}$ grating. The laser power used was $3 \mathrm{~mW}$ at the stage. All reported spectra underwent baseline correction to remove fluorescence contamination and 5-point adjacent averaging smoothing. The experiments were done on the powdered samples deposited on a silicon wafer.

2.2.5. X-Ray Photoelectron Spectroscopy (XPS): The XPS measurements on the materials of the electrodes( (non-oxidized (C-B) and air oxidized (C-AO) carbons): initial, after wetting in water 
(denoted as "w") and $\mathrm{H}_{2} \mathrm{SO}_{4}$ (denoted as "a") and after running $\mathrm{CV}$ and chronoamperometry under on/off illumination experiments) were carried out on a Kratos Axis-Ultra spectrometer, using a monochromatic $\mathrm{Al} \mathrm{Ka}$ source $(1487 \mathrm{eV})$ operating at $15 \mathrm{kV}$ and $14 \mathrm{~mA}, 10^{-8}$ Pa vacuum in the analyser chamber and an analysis spot size of $300 \times 700 \mu \mathrm{m}$. Spectrometer pass energy of $40 \mathrm{eV}$ was used for all elemental spectral regions, whilst $160 \mathrm{eV}$ pass energy was used for the survey spectra used for surface atomic concentration calculation. The binding energy scale of spectrometer was calibrated using the metallic $\mathrm{Cu} 2 \mathrm{p}_{3 / 2}$ and $\mathrm{Cu} 3 \mathrm{p}_{3 / 2}$ lines and Au Fermi Edge of the respective reference metals. All measurements were performed at a take-off angle of $90^{\circ}$. The CasaXPS (version 2.3.5) and Multipack software was used to fit photoelectron spectra. Many organic materials, and their surfaces, contain species that are sensitive to prolonged X-ray exposure, particularly under ultra-high vacuum conditions. In all analyses presented in this study, the sample stage temperature was reduced to less than $-120{ }^{\circ} \mathrm{C}$ using a liquid nitrogen cooling system. This has been shown to preserve the chemical environment of matrix and adsorbed elements for periods far longer than data collection times [31], even with X-ray intensities experienced on synchrotron sources [32].

2.2.6. Fourier transform infrared (FT-IR) spectroscopy: FTIR was carried out on the active carbon components of the electrodes using a Nicolet Magna-IR 830 spectrometer using the attenuated total reflectance (ATR) method. The spectrum was generated and collected 64 times and corrected for the background noise. The experiments were done on the powdered samples, without $\mathrm{KBr}$ addition.

2.2.7. Potentiometric titration: Potentiometric titration measurements were performed on the active carbon components of the electrodes with a 888 Titrando automatic titrator (Metrohm). The details on the experiments are presented in Reference [22]. The experimental data were 
transformed into a proton binding curves, $Q$, representing the total amount of protonated sites. From them the $\mathrm{pK}_{\mathrm{a}}$ distributions and the numbers of groups represented by certain $\mathrm{pK}_{\mathrm{a}}$ values were calculated [33, 34].

2.2.8. Thermal analysis-mass spectrometry (TA-MS): Thermogravimetric (TG) curves were obtained using a TA instrument thermal analyzer (SDT Q 600), which was connected to a gas analysis system (OMNI Star ${ }^{\mathrm{TM}}$ ) mass spectrometer. The active carbon components were heated up to $1000{ }^{\circ} \mathrm{C}\left(10{ }^{\circ} \mathrm{C} / \mathrm{min}\right)$ under a constant helium flow $(100 \mathrm{~mL} / \mathrm{min})$. From the TG curves, differential TG (DTG) curves were derived. The composition of gases was evaluated by MS and gas evolution profiles as a function of temperature were obtained.

2.2.9. High-resolution transmission electron microscopy (HR-TEM): HR-TEM was performed on the active carbon components of the electrodes on a JEOL 2100 LaB6 instrument operating at $200 \mathrm{kV}$. Analyses were performed after the carbon samples were resuspended in ethanol.

\section{Results and discussion}

\subsection{Characterization of the nanoporous carbons}

The surface properties of the active carbon components of the electrodes are summarized in Tables 1-3 and in Figure 1. The measured nitrogen adsorption-desorption isotherms are collected in Figure S1 of Supplementary Information The porosity data collected in Table 1 show C-A as a nonporous carbon and C-B as a material of low porosity.. After air oxidation at $350{ }^{\circ} \mathrm{C}$ the porosity significantly increased and C-A is more susceptible for activation with oxygen than C-B. After this process micropores, especially pores smaller than $0.7 \mathrm{~nm}$, are formed. These pores have been indicated as important for the capacitive performance [17, 20]. 
Table 1. The parameters of porous structure calculated from nitrogen adsorption isotherms for the initial active carbon materials and those wetted with sulfuric acid.

\begin{tabular}{lcccccc}
\hline Sample & $\begin{array}{c}\mathrm{S}_{\mathrm{BET}} \\
\left(\mathrm{m}^{2} / \mathrm{g}\right)\end{array}$ & $\begin{array}{c}\mathrm{V}_{\mathrm{t}} \\
\left(\mathrm{cm}^{3} / \mathrm{g}\right)\end{array}$ & $\begin{array}{c}\mathrm{V}_{\text {meso }} \\
\left(\mathrm{cm}^{3} / \mathrm{g}\right)\end{array}$ & $\begin{array}{c}\mathrm{V}_{<0.7 \mathrm{~nm}} \\
\left(\mathrm{~cm}^{3} / \mathrm{g}\right)\end{array}$ & $\begin{array}{c}\mathrm{V}_{<1 \mathrm{~nm}} \\
\left(\mathrm{~cm}^{3} / \mathrm{g}\right)\end{array}$ & $\begin{array}{c}\mathrm{V}_{\text {mic }}(\mathrm{DFT}) \\
\left(\mathrm{cm}^{3} / \mathrm{g}\right)\end{array}$ \\
\hline $\mathrm{C}-\mathrm{A}$ & 38 & 0.022 & 0.021 & 0.000 & 0.000 & 0.001 \\
$\mathrm{C}-\mathrm{A}-\mathrm{H}_{2} \mathrm{SO}_{4}$ & 14 & 0.032 & 0.031 & 0.000 & 0.000 & 0.001 \\
$\mathrm{C}-\mathrm{AO}$ & 727 & 0.363 & 0.103 & 0.150 & 0.184 & 0.260 \\
$\mathrm{C}-\mathrm{AO}-\mathrm{H}_{2} \mathrm{SO}_{4}$ & 708 & 0.366 & 0.095 & 0.152 & 0.193 & 0.271 \\
$\mathrm{C}-\mathrm{B}$ & 290 & 0.157 & 0.062 & 0.036 & 0.059 & 0.095 \\
$\mathrm{C}-\mathrm{B}-\mathrm{H}_{2} \mathrm{SO}_{4}$ & 182 & 0.141 & 0.078 & 0.000 & 0.023 & 0.063 \\
$\mathrm{C}-\mathrm{BO}$ & 847 & 0.458 & 0.149 & 0.181 & 0.239 & 0.309 \\
$\mathrm{C}-\mathrm{BO}-\mathrm{H}_{2} \mathrm{SO}_{4}$ & 846 & 0.466 & 0.135 & 0.197 & 0.258 & 0.331 \\
\hline
\end{tabular}

The contents of elements on the surface of the active components obtained from XPS are listed in Table 2. The results of deconvolution of $\mathrm{C} 1 s, \mathrm{O} 1 s, \mathrm{~N} 1 s$ and $\mathrm{S} 2 p$ core energy levels are summarized in Table 3. The results show that the C-B sample has more nitrogen and sulfur than C-A does. After activation the content of oxygen on the surface doubles for the later sample and stays constant on the former one. Comparison of the results after deconvolution of $\mathrm{C} 1 \mathrm{~s}$ and $\mathrm{O} 1 \mathrm{~s}$ core energy levels for C-A and C-B, which have similar contents of carbon and oxygen, shows that the latter has more carboxylic and ether groups (Table 3). A significant content of oxygen in the former sample is in sulfur-oxygen compounds. This is consistent with the results of the deconvolution of S $2 p$ core energy levels for these two samples (Figure 1), which show higher contributions of sulfoxides/sulfones and sulfonic acids on the surface of C-A than those on C-B. On the other hand, C-B has much more bisulfides/sulfides and thioethers. After air activation the contributions of bisulfides/sulfides and thioethers increase significantly, especially for C-AO 
with a marked decrease in sulfoxides and sulfones for both samples. Analysis of the $\mathrm{O} 1 \mathrm{~s}$ core energy levels suggests that oxygen in carboxyl/carbonyl groups increases for both samples and for $\mathrm{C}-\mathrm{BO}$ an increase in the contribution of thioethers is also found. The main differences in the distribution of nitrogen species derived from the deconvolution of $\mathrm{N} 1 \mathrm{~s}$ core energy levels (Figure 1, Table 3) is in the amount of pyridine and pyridine-N-oxide. While the former species are predominant in $\mathrm{C}-\mathrm{B}$, the latter are in a larger quantity in the $\mathrm{C}$-A sample. After oxidation the distribution of nitrogen species is quite similar for both samples with the predominance of pyrrolic/pyridine and pyridone nitrogen on the surface. Of course, the effects of Faradaic reactions of these nitrogen groups [21, 22, 35] and their electronic properties on the electron transfer [21] for the overall capacitance should be the most important for the C-B series of samples owing to twice as much nitrogen on the surface than on the surfaces of the C-A series of samples.

Table 2. Content of elements on the surface (in at. \% from XPS analysis).

\begin{tabular}{lcccc}
\hline Sample & $\mathrm{C}$ & $\mathrm{O}$ & $\mathrm{N}$ & $\mathrm{S}$ \\
\hline C-A & 87.8 & 8.6 & 1.3 & 1.7 \\
C-AO & 81.4 & 16.6 & 1.2 & 0.7 \\
C-B & 86.0 & 9.3 & 2.4 & 2.4 \\
C-BO & 87.3 & 9.3 & 2.6 & 0.9 \\
\hline
\end{tabular}

Table 3. The results of deconvolution of C $1 s, \mathrm{O} 1 s, \mathrm{~N} 1 \mathrm{~s}$ and S $2 p$ core energy levels.

\begin{tabular}{llllll}
\hline Energy, eV & Bond assignment & C-A & C-B & C-AO & C-BO \\
\hline
\end{tabular}




\begin{tabular}{|c|c|c|c|c|c|}
\hline \multicolumn{6}{|l|}{ C $1 s$} \\
\hline 284.8 & C-(C, S) (graphitic carbon) & 77.9 & 71.0 & 68.0 & 66.7 \\
\hline 286.3 & C- $(\mathrm{O}, \mathrm{N}, \mathrm{S}, \mathrm{H})$ (phenolic, alcoholic, etheric) & 13.7 & 14.2 & 16.0 & 16.0 \\
\hline 287.6 & $\mathrm{C}=\mathrm{O}$ (carbonyl or quinone) & 5.3 & 5.7 & 7.7 & 6.7 \\
\hline 289.2 & $\mathrm{O}-\mathrm{C}=\mathrm{O}$ (carboxyl or ester) & 3.0 & 6.0 & 4.9 & 6.6 \\
\hline 291.0 & $\pi-\pi^{*}$ & ND & 3.0 & 3.3 & 4.0 \\
\hline \multicolumn{6}{|l|}{ O 1s } \\
\hline 531.5 & $\begin{array}{l}\mathrm{O}=\mathrm{C} / \mathrm{O}=\mathrm{S} \text { (in carbonyl/quinone or } \\
\text { sulfoxides/ sulfones) }\end{array}$ & 40.9 & 40.7 & 43.6 & 48.5 \\
\hline 533.6 & $\begin{array}{l}\text { O-C/O-S (in phenol/epoxy or } \\
\text { thioethers/sulfonic) }\end{array}$ & 51.5 & 40.0 & 49.9 & 47.1 \\
\hline 535 & $\begin{array}{l}\text {-O- (in carboxyl, water or chemisorbed } \\
\text { oxygen species) }\end{array}$ & 7.6 & 19.3 & ND & 4.4 \\
\hline 536.3 & $\begin{array}{l}\text { adsorbed water or oxygen, } \mathrm{C}=\mathrm{O} \text { (occluded } \\
\mathrm{CO} \text { or } \mathrm{CO}_{2} \text { ) }\end{array}$ & ND & ND & 6.5 & ND \\
\hline \multicolumn{6}{|c|}{ 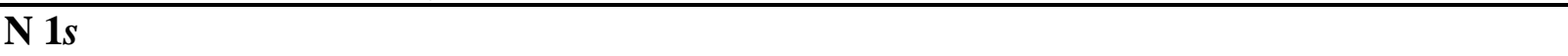 } \\
\hline 398.7 & N-6 (in pyridine) & 20.4 & 26.8 & 29.0 & 31.0 \\
\hline 400.2 & N-5 (in pyrrolic/pyridone and azo nitrogen) & 30.5 & 30.0 & 42.9 & 39.6 \\
\hline 401.5 & $\mathrm{~N}-\mathrm{Q}$ (in quaternary) & 35.9 & 35.3 & 23.9 & 24.1 \\
\hline 403.1 & $\mathrm{~N}-\mathrm{X}$ (in pyridine- $\mathrm{N}$-oxide) & 13.2 & 8.0 & 4.2 & 5.3 \\
\hline \multicolumn{6}{|l|}{$\mathrm{S} 2 p_{3 / 2}$} \\
\hline 163.9 & R-S-S- (in thiol, bisulfides configuration) & 40.4 & 63.7 & 81.4 & 73.2 \\
\hline 165.1 & $\mathrm{C}-\mathrm{S}-\mathrm{C} / \mathrm{R}-\mathrm{S}_{2}-\mathrm{OR}$ (in sulfides and thioethers) & 6.4 & 10.3 & 6.7 & 15.6 \\
\hline 167.3 & $\mathrm{R}_{2}-\mathrm{S}=\mathrm{O} / \mathrm{R}-\mathrm{SO}_{2}-\mathrm{R}$ (in sulfoxides, sulfones) & 19.6 & 11.6 & 7.5 & 9.4 \\
\hline 168.8 & $\mathrm{R}-\mathrm{SO}_{3} \mathrm{H} / \mathrm{SO}_{4}{ }^{2-}$ (in sulfonic acids, sulphate) & 32.7 & 14.3 & 4.4 & 2.9 \\
\hline
\end{tabular}



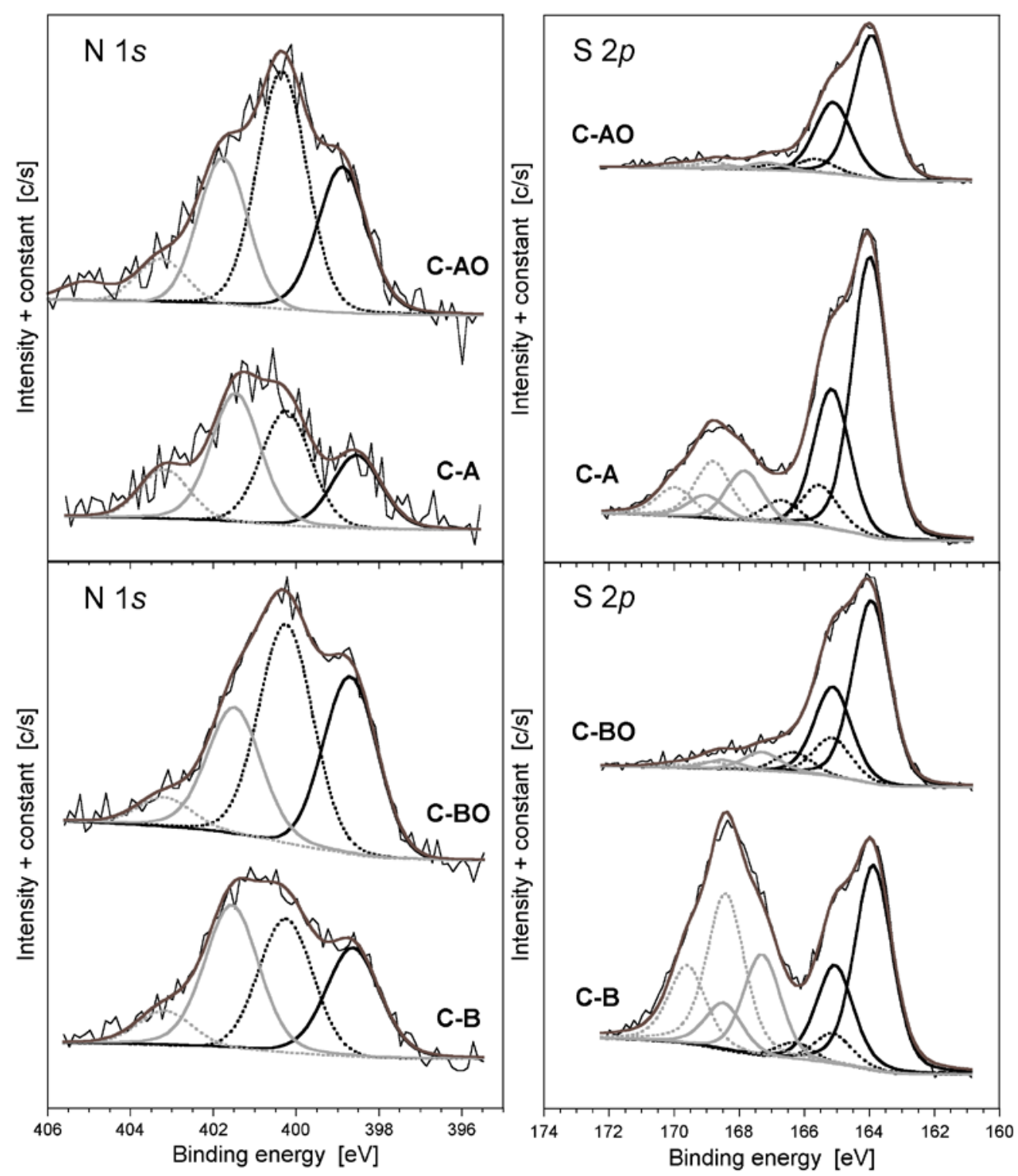

Figure 1. N 1s and S $2 p$ core energy levels.

The result of TA analyzes and the mass spectra for the initial active carbon components are collected in Figures 2 and 3. They show the changes in the chemistry of our samples. As seen on DTG curves, treatment of the initial carbons at $350{ }^{\circ} \mathrm{C}$ removes the low temperature decomposing groups, which are in the case of carbons considered as the most acidic ones, and creates a significant number of groups decomposing between 400 and $800{ }^{\circ} \mathrm{C}$. Based on the 
chemistry of the carbon precursors and XPS results and for the clarity of discussion, the mass spectra thermal profiles chosen for analysis are those at $m / z 44,28,48,64,18,17$ and 16 . They can be linked to $\mathrm{CO}_{2}, \mathrm{CO} / \mathrm{N}_{2}, \mathrm{SO}, \mathrm{SO}_{2}, \mathrm{H}_{2} \mathrm{O}, \mathrm{NH}_{3}$ or $\mathrm{OH}$ and $\mathrm{NH}_{2}$ or $\mathrm{O}$, respectively. The thermal profiles of $\mathrm{m} / \mathrm{z} 17$ and 16 exhibit two distinctive features. The first occurs at temperatures below $100{ }^{\circ} \mathrm{C}$ and is attributed to loss of adsorbed water. The second occurs at around $190{ }^{\circ} \mathrm{C}$ and besides water a thermal decomposition of nitrogen-containing functionalities, amines/amides might contribute to it. As seen for the C-A series, activation resulted in a disappearance of the sulfoxides, sulfones and sulfonic acids decomposing at about $260{ }^{\circ} \mathrm{C}$ [24]. At this temperature, also carboxylic acids [36] and amines/amides [37] decompose. In the activated sample, C-AO, $\mathrm{NH}_{2}, \mathrm{CO}$ and $\mathrm{CO}_{2}$ are removed from stable pyrroles/pyridones, quinones, carbonyls and ethers between 400 and $800{ }^{\circ} \mathrm{C}$ [36, 38]. The sulfur species, if present, are not detected or do not decompose at the experimental thermal analysis window. On the surface of C-B there are much more sulfonic acids/sulfoxides and sulfones than on that of C-A. The removal of $\mathrm{NH}_{3}$ at low temperature has also more complex pattern clearly indicating various groups releasing this species as a result of reduction processes. After air activation the profiles of nitrogen containing species at low temperature still show intense signals and, as in the case of CAO a signal from sulfur species has a very low intensity. These results clearly show that air activation at $350{ }^{\circ} \mathrm{C}$ significantly affects the speciation of sulfur compounds present on the surface of our materials. Apparently more nitrogen than sulfur should be present on the surface of activated carbon samples than that of non-activated. 

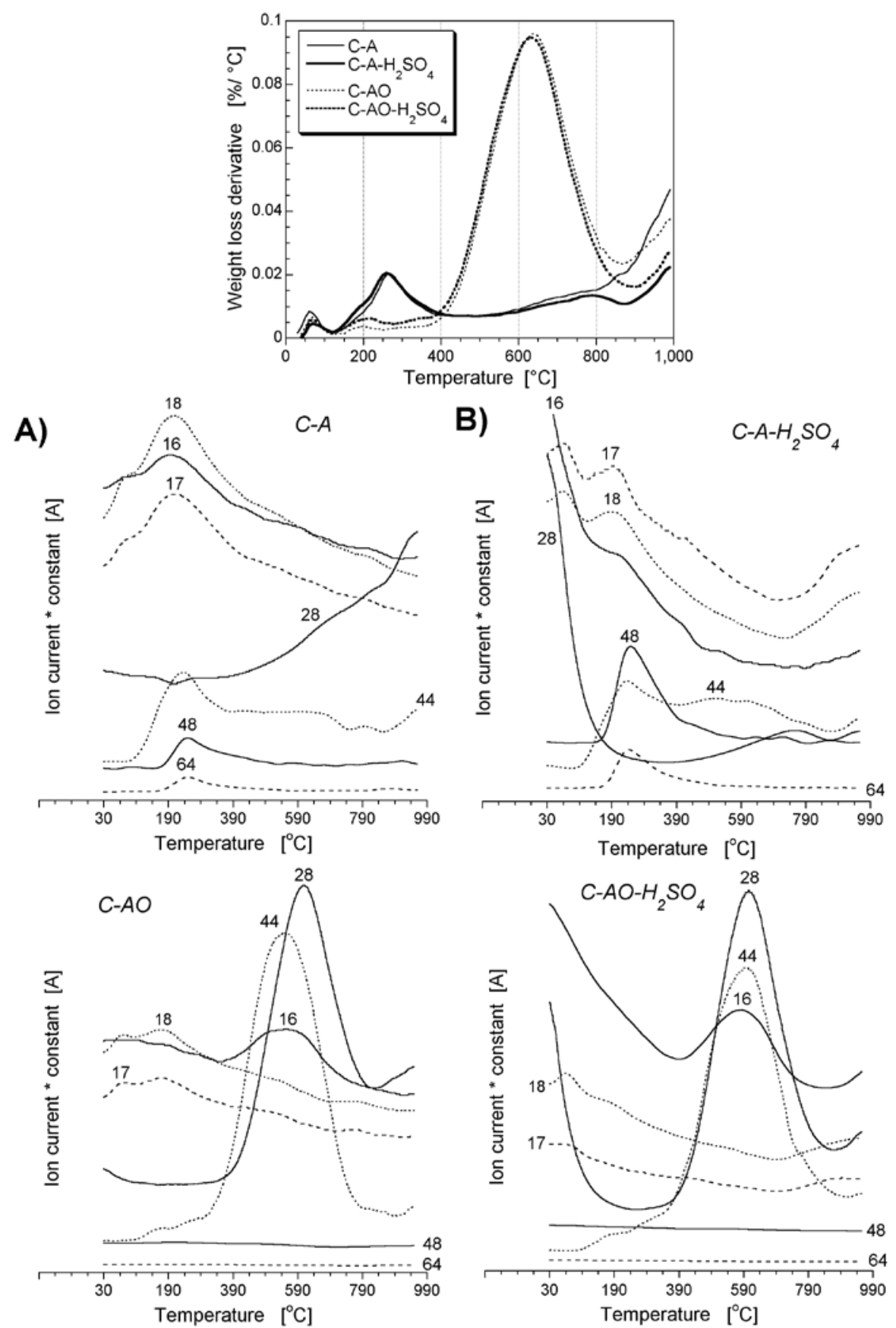

$16-\mathrm{NH}_{2} ; 17-\mathrm{NH}_{3} ; 18-\mathrm{H}_{2} \mathrm{O} ; 28-\mathrm{CO} / \mathrm{N}_{2}$;

$44-\mathrm{CO}_{2} ; 48-\mathrm{SO} ; 64-\mathrm{SO}_{2}$

Figure 2. TA and mass spectra thermal profiles for the C-A series of carbons. A) - initial, B) after wetting in sulfuric acid (multiplication factor: MW-16 x 7; MW-17 x 3; MW-18 x 1; MW28 x 1; MW-44 x 5; MW-48 x 50; MW-64 x 11). 

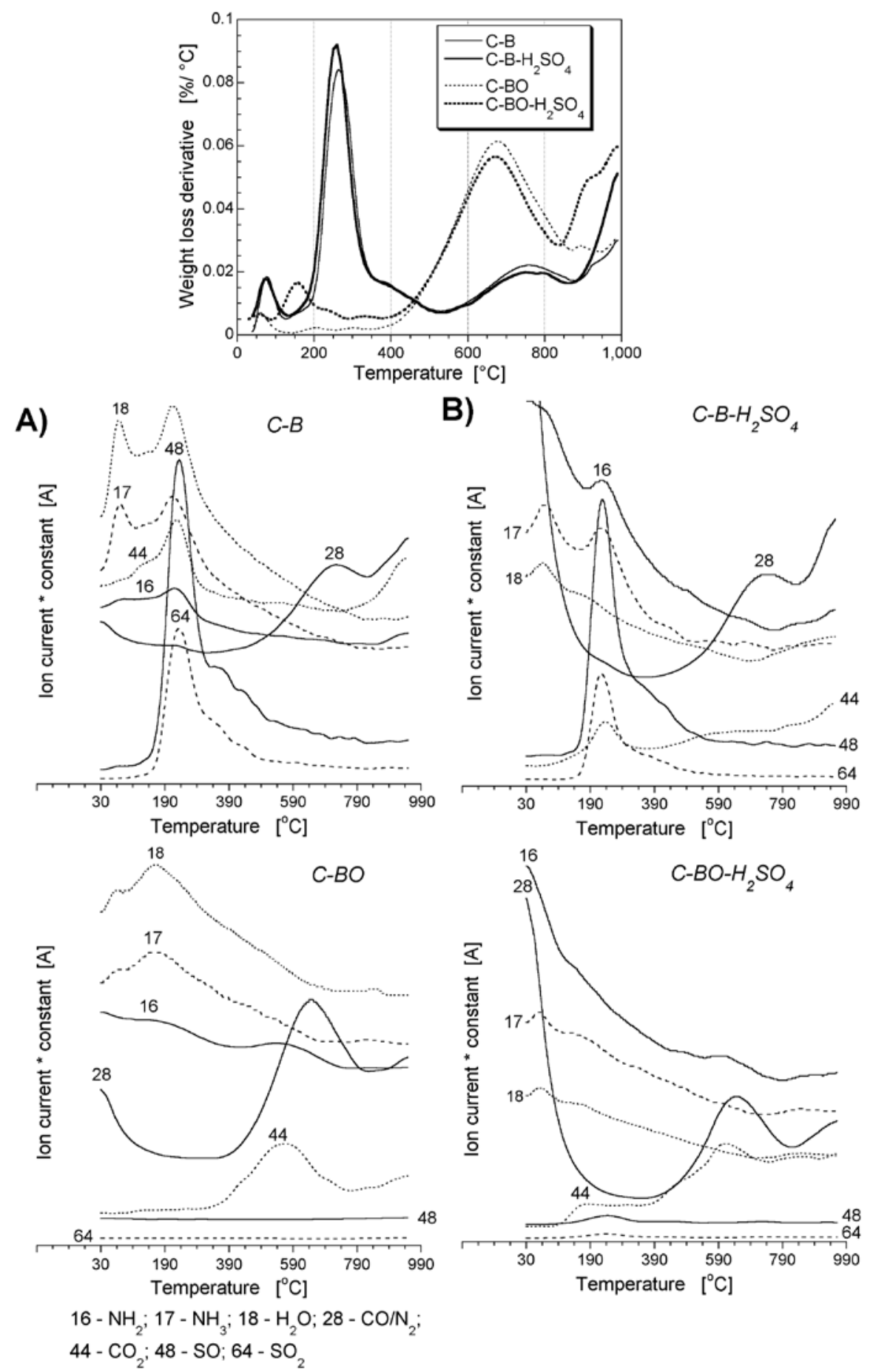

$16-\mathrm{NH}_{2} ; 17-\mathrm{NH}_{3} ; 18-\mathrm{H}_{2} \mathrm{O} ; 28-\mathrm{CO}_{2}$

Figure 3. TA and mass spectra thermal profiles for the C-B series of carbons. A) - initial, B) after wetting in sulfuric acid (multiplication factor: MW-16 x 7; MW-17 x 3; MW-18 x 1; MW28 x 1; MW-44 x 5; MW-48 x 50; MW-64 x 11). 
The synthesized carbons have a some level of graphitization, which is seen on XRD diffraction patterns and Raman spectra (Figure 4), and on the HR-TEM images (Figure 5). G and D bands are clearly visible at $1590 \mathrm{~cm}^{-1}$ and $1360 \mathrm{~cm}^{-1}$, respectively. A higher disorder of initial carbons is represented by the broader $\mathrm{G}$ band and higher relative intensity of the D band in comparison with that of the $\mathrm{G}$ band. As seen, after oxidation at $350{ }^{\circ} \mathrm{C}$ the $\mathrm{I}_{\mathrm{D}} / \mathrm{I}_{\mathrm{G}}$ ratio $(0.89$ for $\mathrm{C}$-AO and 0.88 for C-BO) decreased compared to the initial materials. This might be related to the removal of amorphous carbon impurities. The narrow G band suggests the presence of some ordered graphitic-like units in these carbon materials [39]. In the HR-TEM images the well defined “dots” of 5-10 nm of graphitic domains are visible.

A)
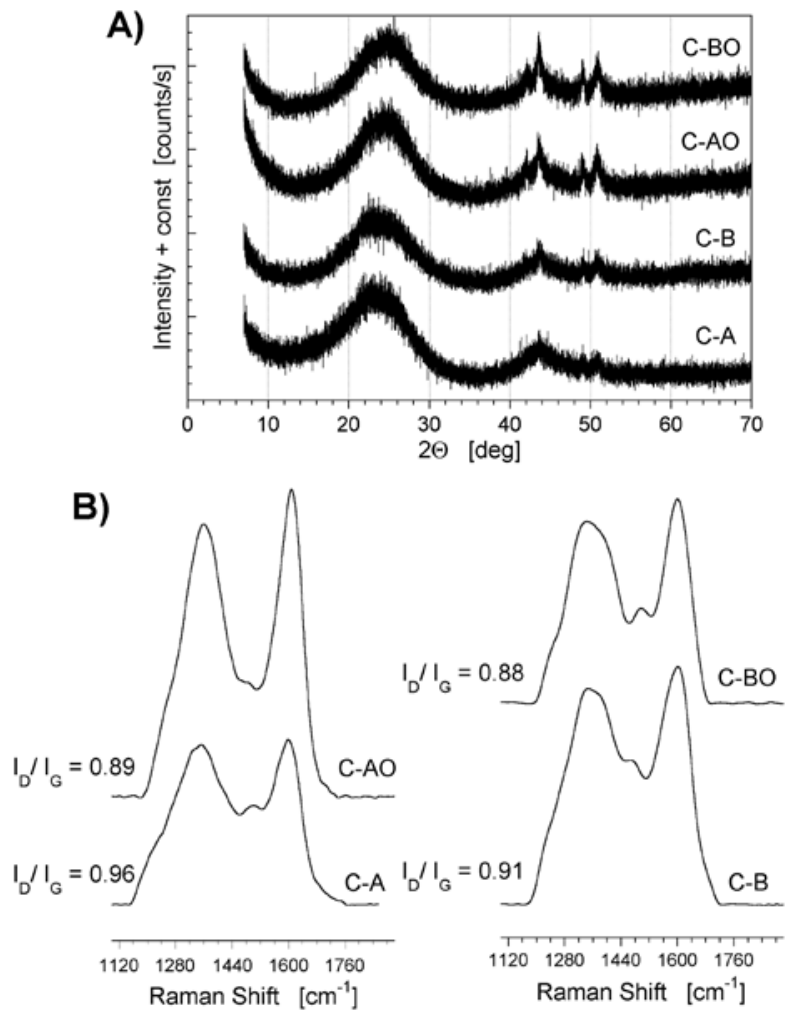

Figure 4. A) X-Ray diffraction patterns and B) Raman spectra. 


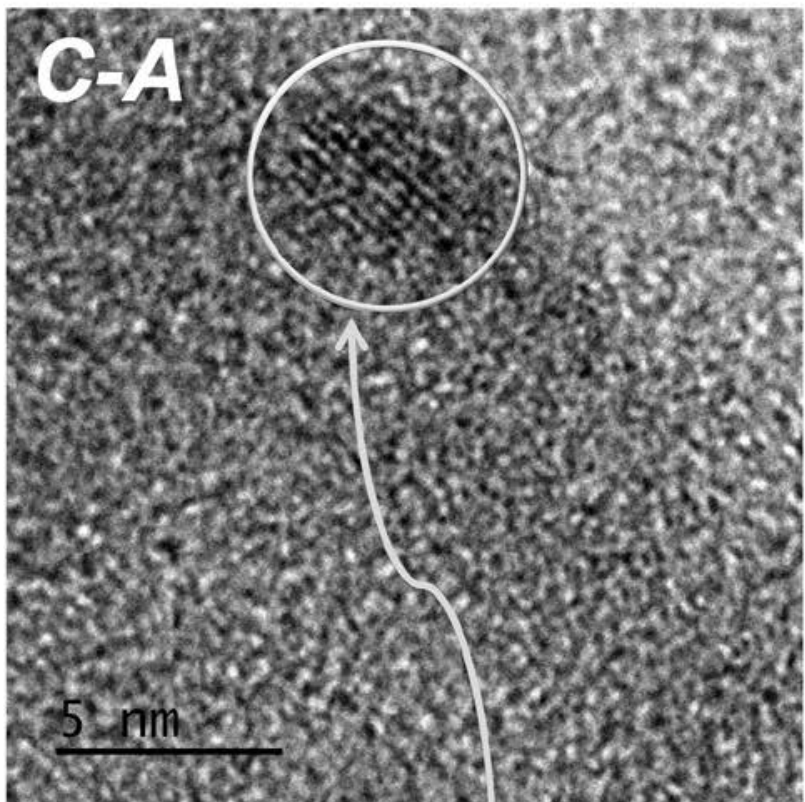

GRAPHITIC DOMAINS

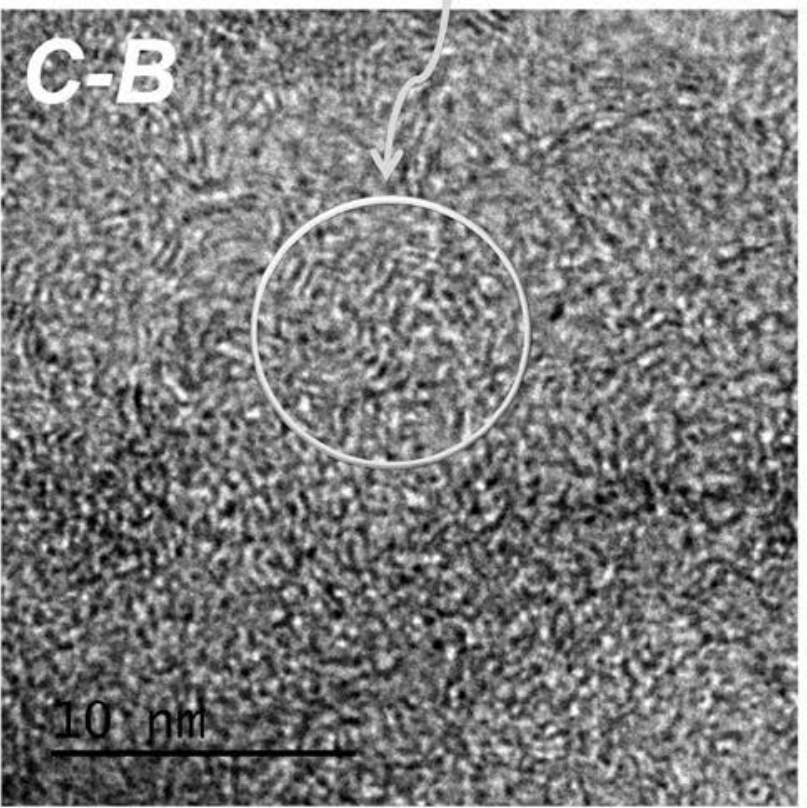

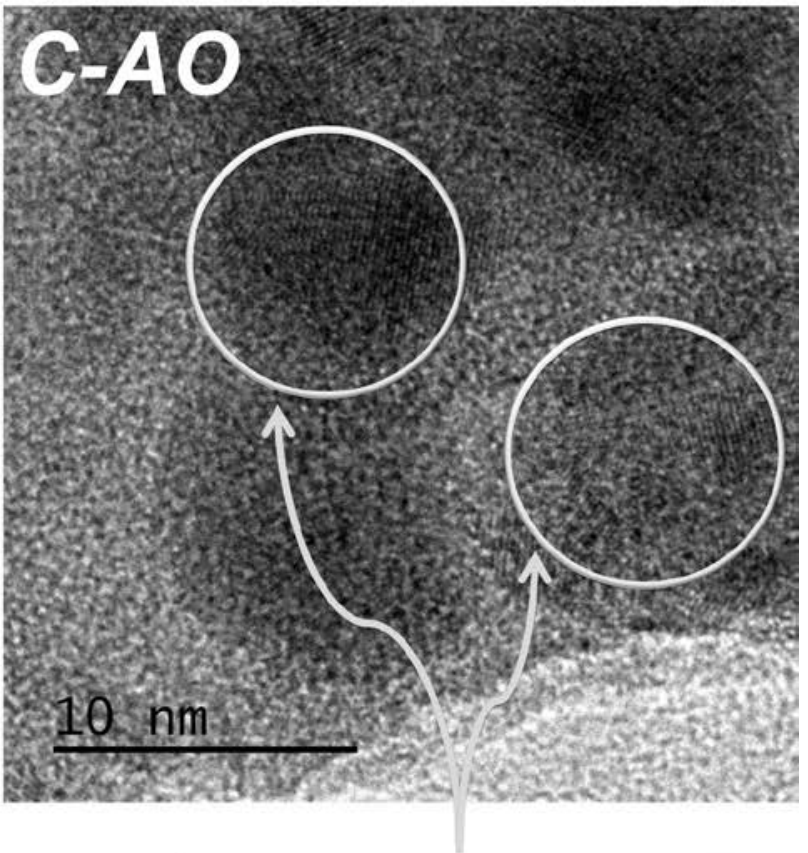

GRAPHITIC DOMAINS

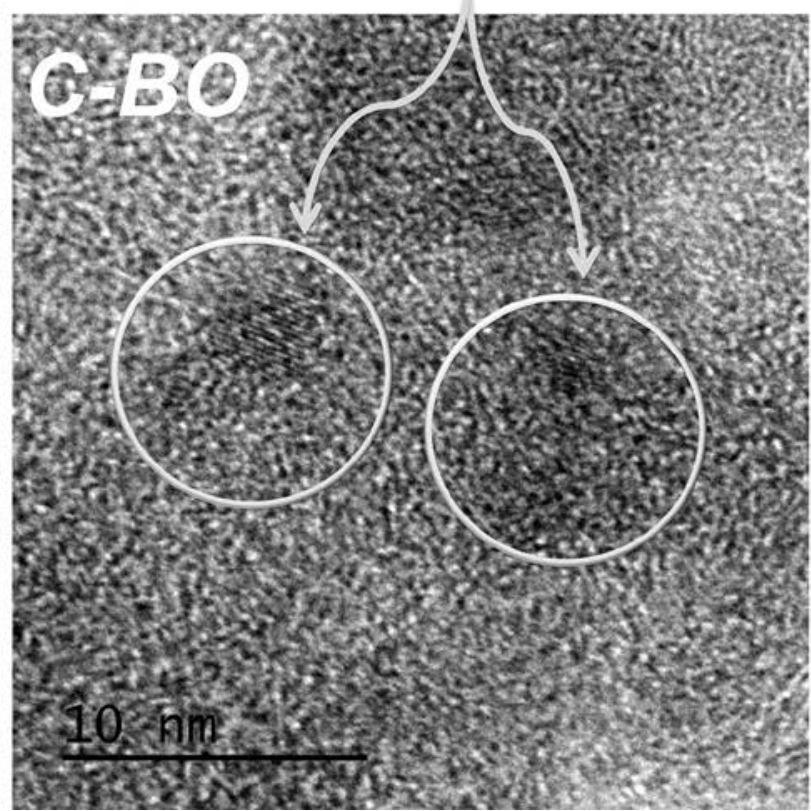

Figure 5. HR-TEM images. 


\subsection{Capacitive performance and the effect of wetting}

Since the full accessibility of an electrode pore system to electrolyte ions is of paramount importance for the stability of a capacitor, and owing to the fact that we use the water solution of sulfuric acid, the built electrodes were soaked either in the electrolyte or in distilled water for 72 hours before the experiments were run either under solar irradiation or in dark. Prior to cyclic voltammetry (CV) measurements the open circuit potentials (OCP) vs. $\mathrm{Ag} / \mathrm{AgCl}$ were recorded in $1 \mathrm{M} \mathrm{H}_{2} \mathrm{SO}_{4}$. Constant values of OCP were accepted as indicators of the entirely wet surface. Then the CVs were run in a very narrow potential window (from $0.2 \mathrm{~V}$ to $-0.2 \mathrm{~V}$ ) with gradual increase of the potential range $(0.2 \mathrm{~V})$ to avoid polarization of the electrode. The cyclic voltammetry experiments confirmed the stability of the system (Figure S2 of Supplementary Information). Even after wetting with water the stability of the samples in the electrolyte was reached very quickly owing to the initial acid concentration gradient in the system and thus a fast movement of ions to the pores filled with the solvent. Obtained CV curves are compared in Figure 6. As seen, there are significant differences in the shapes of the curves between C-A and other carbons. Especially C-B shows the clear rectangular shape after wetting in water indicating the capacitive performance. The initial carbon C-A and C-B, on the other hand, and air oxidized carbon (C-AO) shows the charge transfer limitations after wetting in sulfuric acid. This might be related either to limitation in pore accessibility (for C-A) or a decrease in the conductivity of carbon matrix owing to the incorporation of more oxygen as a result of air activation (for C-AO). Another significant feature is the presence of the redox humps at $0.38 \mathrm{~V}$ vs. $\mathrm{Ag} / \mathrm{AgCl}$ on the rectangular curves obtained after equilibration in water and in the electrolyte. These are linked to Faradaic reactions on the functional groups of carbons such as quinones [16]. The surface chemistry aspect is addressed later in this paper. 
Even though the effect of light exposure is hardly seen on the overall CV curves owing to the good capacitive performance, the magnification of the curves presented in Figure 6 shows the peak at about $0.12-0.15 \mathrm{~V}$ vs. $\mathrm{Ag} / \mathrm{AgCl}$, which appears only under solar light irradiation. This suggests the occurrence of a reduction reaction promoted by visible light (VL). That peak is especially visible for the $\mathrm{C}-\mathrm{B}$ and $\mathrm{C}-\mathrm{BO}$ carbon samples after wetting in sulfuric acid. The presence of this peak is linked to the oxygen reduction reaction [40, 41]. To confirm this, the CV experiments were run in the electrolyte without oxygen in dark and under VL conditions (purged with nitrogen) and the hump at $0.12-0.15 \mathrm{~V}$ vs. $\mathrm{Ag} / \mathrm{AgCl}$ was not detected (Figure S3 of Supplementary Information). Besides that, the broadening of the CV curves is seen in the potential window from $0.3 \mathrm{~V}$ to $-0.2 \mathrm{~V}$ upon visible light illumination. 

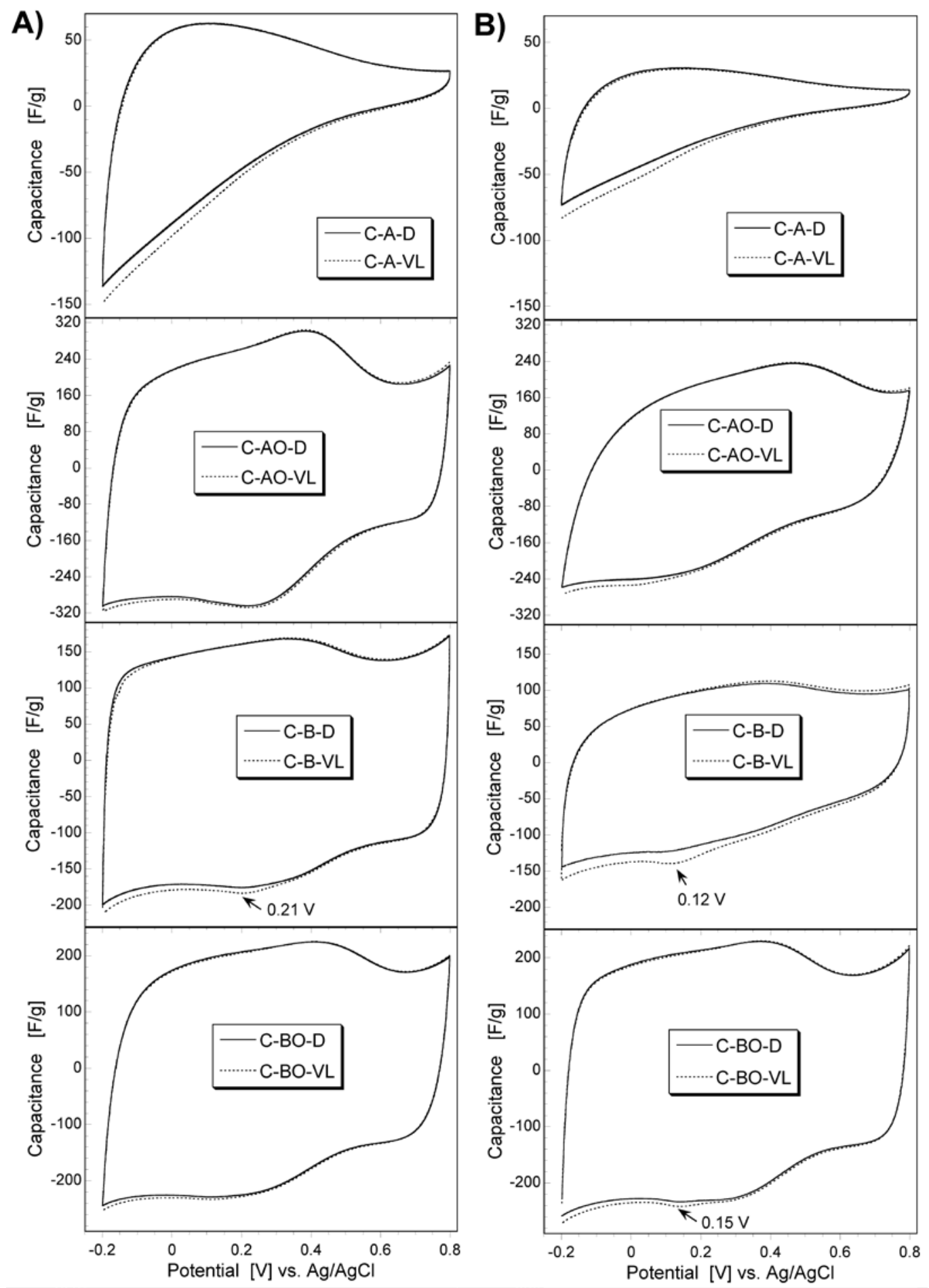

Figure 6. The CV curves measured after wetting in water (A) and in sulfuric acid (B) at the scan rate of $5 \mathrm{mV} / \mathrm{s}$ in dark - D and under visible light - VL exposure. 
The calculated capacitance values are collected in Table 4. The capacitance is especially high after wetting in water. Exposure to visible light results only in a small, but consistent increase in the performance and that increase is more pronounced after wetting in sulfuric acid. Wetting in the electrolyte resulted in $35 \%$ and about $50 \%$ decrease in the performance for the initial C-B and C-A carbons, respectively, in comparison with the results obtained after wetting in water. For $\mathrm{C}-\mathrm{AO}$ the decrease in the capacitance is $25 \%$. On the other hand, in the case of C-BO a slight increase is noticed after wetting in sulfuric acid in comparison with wetting in water. The trend observed for the initial carbons is quite interesting because an extended treatment with sulfuric acid in the case of the carbons whose active sites are unsaturated with oxygen would result in surface oxidation. This effect might influence the discussion of the mechanism of the charge storage, for which the actual surface chemistry and porosity of carbons should be taken into consideration. That possible addition of new surface functional groups, especially when pores are very small, would cause pore blocking and kinetic limitations for the electrolyte ions to enter them. The pseudocapacitive performance could be also affected. Owing to these factors, the surface of the active carbon materials exposed to $\mathrm{H}_{2} \mathrm{SO}_{4}$ wetting has been analyzed in details.

It has to be mentioned here that the capacitance values measured for our carbons are higher than those measured on nitrogen doped microporous carbons (306 F/g in $2 \mathrm{M} \mathrm{H}_{2} \mathrm{SO}_{4}$ ) [42], mesoporous carbons (182 F/g in $1 \mathrm{M} \mathrm{H}_{2} \mathrm{SO}_{4}$ ) [43], sulfur doped carbons (206 F/g in $2 \mathrm{M} \mathrm{H}_{2} \mathrm{SO}_{4}$ and $191 \mathrm{~F} / \mathrm{g}$ in $6 \mathrm{M} \mathrm{KOH}$ [4, 24] and recently addressed S- and $\mathrm{N}$ - doped carbons. On the latter ones the values reaching $140 \mathrm{~F} / \mathrm{g}$ in $1 \mathrm{M} \mathrm{H}_{2} \mathrm{SO}_{4}$ [44], $320 \mathrm{~F} / \mathrm{g}$ in $2 \mathrm{M} \mathrm{KOH} \mathrm{[45],} 264 \mathrm{~F} / \mathrm{g}$ in $6 \mathrm{M}$ $\mathrm{KOH}[46]$ have been reported. 
Since the initial carbon C-A can be considered as nonporous with no volume in pores smaller than $1 \mathrm{~nm}$, the specific capacitance of about $90 \mathrm{~F} / \mathrm{g}$ measured on it indicates that its surface chemistry must be a crucial factor. The importance of surface chemistry is also seen in the fact that no dependence of the capacitance on the volume of micropores or ultramicropores was found for the materials tested. Therefore the details on the nature of surface chemical functionalities on the carbons tested should be analyzed.

Table 4. The specific capacitance values (in F/g) measured after wetting in water or sulfuric acid in dark or under visible light before and after chronoamperometry response upon on/off illumination.

\begin{tabular}{lcccc}
\hline Sample & $\begin{array}{c}\text { Dark/Wet in } \\
\mathrm{H}_{2} \mathrm{O}\end{array}$ & $\begin{array}{c}\text { Light/Wet in } \\
\mathrm{H}_{2} \mathrm{O}\end{array}$ & $\begin{array}{c}\text { Dark/Wet in } \\
\mathrm{H}_{2} \mathrm{SO}_{4}\end{array}$ & $\begin{array}{c}\text { Light/Wet in } \\
\mathrm{H}_{2} \mathrm{SO}_{4}\end{array}$ \\
\hline \multicolumn{5}{c}{ Before chronoamperometry response } \\
\hline C-A & 89 & 95 & 46 & 51 \\
C-AO & 450 & 455 & 337 & 344 \\
C-B & 294 & 302 & 179 & 191 \\
C-BO & 365 & 369 & 382 & 390 \\
\hline \multicolumn{5}{c}{ After chronoamperometry response } \\
\hline C-A & 140 & 145 & 105 \\
C-AO & 462 & 464 & 348 & 109 \\
C-B & 298 & 303 & 229 & 353 \\
C-BO & 368 & 370 & 392 & 395 \\
\hline
\end{tabular}

The potentiometric titration results for the active carbon materials are presented in Table 5. As seen, based on the average $\mathrm{pH}$ values, the acidity of the carbons significantly differs and the C-A sample is the least acidic and C-B - the most acidic one among the carbons studied. After 
oxidation in air the C-BO became less acidic than its initial counterpart, even thought the total number of acidic groups increased. Apparently, some strong acids were removed from the surface. On the other hand, on the surface of C-A after oxidation a six fold increase in the number of acidic groups was found with the formation of strong acid sites. Even thought the acidic groups are not really expected to contribute to pseudocapacitance in a reversible way, they were indicated as important for wetting of the carbon surface and increasing the accessibility of the pores for electrode ions [17]. Thus they can influence the capacitance indirectly. Interestingly, when plotting the dependence of the specific capacitance on the number of acidic groups, only for the samples wetted in water a good linear dependence was found (Figure 7). For the samples wetted in $\mathrm{H}_{2} \mathrm{SO}_{4}$ the deviations from linear trend exist owing to possible oxidation reactions and thus an in situ improvement in the wettability. Thus one reason for the small capacitance of the C-A samples might be in a limited access of the electrolyte to the pores. As shown before, the small pores, which are the most important sites for EDLC, do not exist in this sample. Moreover, the water-repelling surface in larger pores (small number of acidic groups) does not have a positive effect on the charge storage. 
Table 5. Potentiometric titration results. The number of groups in mmol/g at each $\mathrm{pH}$ values is given in parenthesis. (The $\mathrm{pH}$ value in the second column is the initial $\mathrm{pH}$ of the carbon suspension used for the titration experiment).

\begin{tabular}{|c|c|c|c|c|c|c|c|c|c|c|}
\hline Sample & $\mathrm{pH}$ & $\mathrm{pK}_{\mathrm{a}} 3-4$ & $\mathrm{pK}_{\mathrm{a}} 4-5$ & $\mathrm{pK}_{\mathrm{a}} 5-6$ & $\mathrm{pK}_{\mathrm{a}} 6-7$ & $\mathrm{pK}_{\mathrm{a}} 7-8$ & $\mathrm{pK}_{\mathrm{a}} 8-9$ & $\mathrm{pK}_{\mathrm{a}} 9-10$ & $\mathrm{pK}_{\mathrm{a}} 10-11$ & All \\
\hline C-A & 5.48 & & & & $\begin{array}{c}6.07 \\
(0.053)\end{array}$ & & & $\begin{array}{c}9.50 \\
(0.088)\end{array}$ & & 0.141 \\
\hline $\mathrm{C}-\mathrm{A}-\mathrm{H}_{2} \mathrm{SO}_{4}$ & 5.92 & & & & $\begin{array}{c}6.27 \\
(0.092) \\
\end{array}$ & & & $\begin{array}{c}9.22 \\
(0.092) \\
\end{array}$ & & 0.184 \\
\hline $\mathrm{C}-\mathrm{AO}$ & 3.53 & & $\begin{array}{c}4.40 \\
(0.151) \\
\end{array}$ & $\begin{array}{c}5.23 \\
(0.099) \\
\end{array}$ & $\begin{array}{c}6.37 \\
(0.224)\end{array}$ & $\begin{array}{c}7.42 \\
(0.221) \\
\end{array}$ & $\begin{array}{c}8.48 \\
(0.146) \\
\end{array}$ & $\begin{array}{c}9.08 \\
(0.152) \\
\end{array}$ & $\begin{array}{c}10.20 \\
(0.374)\end{array}$ & 1.367 \\
\hline $\mathrm{C}-\mathrm{AO}-\mathrm{H}_{2} \mathrm{SO}_{4}$ & 3.49 & & $\begin{array}{c}4.58 \\
(0.212)\end{array}$ & $\begin{array}{c}5.93 \\
(0.187)\end{array}$ & $\begin{array}{c}6.83 \\
(0.197)\end{array}$ & $\begin{array}{c}7.65 \\
(0.190)\end{array}$ & $\begin{array}{c}8.84 \\
(0.305)\end{array}$ & & $\begin{array}{c}10.21 \\
(0.591)\end{array}$ & 1.682 \\
\hline C-B & 2.98 & & $\begin{array}{c}4.24 \\
(0.108)\end{array}$ & $\begin{array}{c}5.12 \\
(0.048) \\
5.96 \\
(0.160) \\
\end{array}$ & & $\begin{array}{c}7.31 \\
(0.128)\end{array}$ & $\begin{array}{c}8.99 \\
(0.135)\end{array}$ & & $\begin{array}{c}10.11 \\
(0.142)\end{array}$ & 0.721 \\
\hline $\mathrm{C}-\mathrm{B}-\mathrm{H}_{2} \mathrm{SO}_{4}$ & 3.08 & & $\begin{array}{c}4.42 \\
(0.170)\end{array}$ & & $\begin{array}{c}6.05 \\
(0.188)\end{array}$ & $\begin{array}{c}7.74 \\
(0.183)\end{array}$ & & $\begin{array}{c}9.33 \\
(0.148) \\
9.98 \\
(0.220)\end{array}$ & & 0.909 \\
\hline $\mathrm{C}-\mathrm{BO}$ & 4.03 & $\begin{array}{c}3.08 \\
(0.075) \\
\end{array}$ & $\begin{array}{c}4.24 \\
(0.066) \\
\end{array}$ & $\begin{array}{c}5.20 \\
(0.094) \\
\end{array}$ & $\begin{array}{c}6.54 \\
(0.143) \\
\end{array}$ & $\begin{array}{c}7.50 \\
(0.165) \\
\end{array}$ & $\begin{array}{c}8.86 \\
(0.143) \\
\end{array}$ & & $\begin{array}{c}10.13 \\
(0.299) \\
\end{array}$ & 0.985 \\
\hline $\mathrm{C}-\mathrm{BO}-\mathrm{H}_{2} \mathrm{SO}_{4}$ & 4.35 & & $\begin{array}{c}4.35 \\
(0.145)\end{array}$ & $\begin{array}{c}5.70 \\
(0.122)\end{array}$ & $\begin{array}{c}6.75 \\
(0.192)\end{array}$ & $\begin{array}{c}7.86 \\
(0.108)\end{array}$ & & $\begin{array}{c}9.01 \\
(0.194) \\
9.66 \\
(0.056)\end{array}$ & $\begin{array}{c}10.33 \\
(0.396)\end{array}$ & 1.213 \\
\hline
\end{tabular}

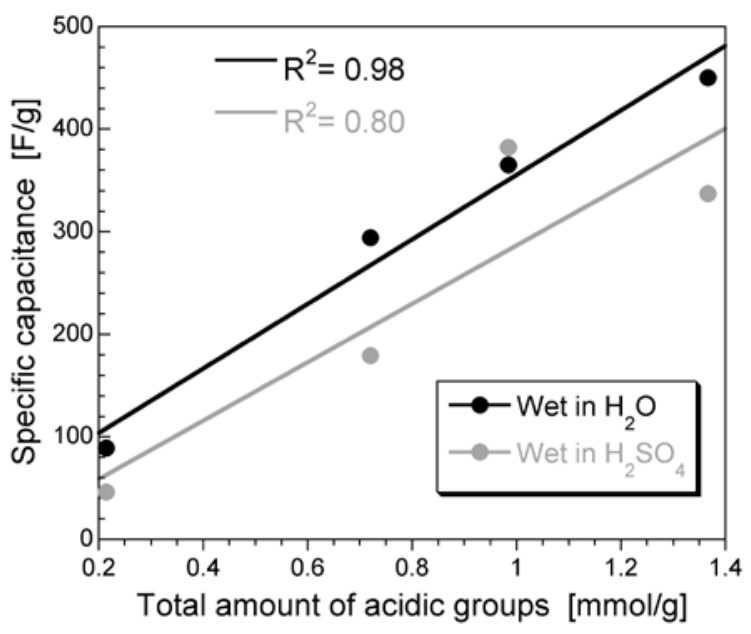

Figure 7. Dependence of the specific capacitance on the number of acidic groups present on the carbon surface. 


\subsection{Surface chemistry}

The detailed analysis of surface chemistry of the active carbon components of the electrodes in conjunction with the measured capacitive performance suggests that the high capacitances of our samples, in spite of the relatively low surface areas, are owing to the effects of the co-doped functional groups containing nitrogen and sulfur [26, 44-46]. The latter should be especially important for the C-A sample of negligible porosity. Its high content of sulfoxides and sulfones results in reversible Faradaic reactions leading to the formation of hydroxylated sulfoxides and sulfoxides, respectively [24].

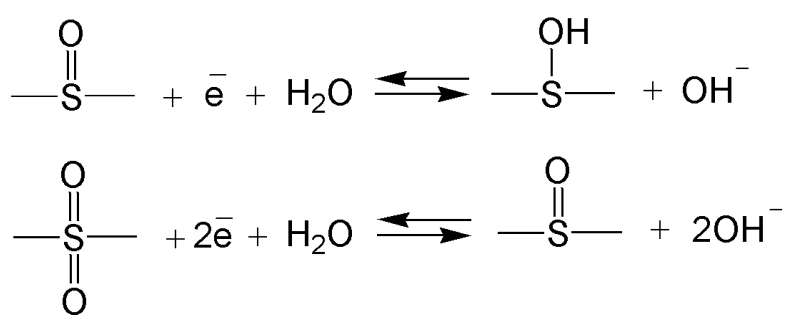

The presence of graphitic units should help with the fast electron transfer through the carbon matrix. A decrease in the capacitance after $\mathrm{H}_{2} \mathrm{SO}_{4}$ wetting could be caused by oxidation of these species by sulfuric acid and formation of bulky sulfonic groups which do not undergo Faradaic reactions and which can block the access of ions to the surface. On the other hand, over $80 \%$ of sulfur on the surface of $\mathrm{C}-\mathrm{AO}$ is in the reduced form as bisulfides, which might exist in the aromatic rings in the small pores and thus bring the positive charge to the neighboring carbon atoms [8, 25-27]. This can explain the highest capacitance measured on this carbon after wetting in water. That positive charge might increase the pore space utilization for sulfate ions $[8,47]$. These reduced sulfur species could be oxidized by sulfuric acid resulting in the change of electronic properties. 
Indeed, as hypothesized above, wetting in sulfuric acid resulted in small but distinctive changes in chemistry. Even though on DTG curves only slight changes are seen for all carbons (Figures 2 and 3), the comparison of the $\mathrm{m} / \mathrm{z}$ thermal profiles shows an increase in the intensity of the signals assigned to the decomposition of oxygen groups $\left(\mathrm{CO}-28\right.$ and $\left.\mathrm{CO}_{2}-44\right)$ and sulfur groups as $\mathrm{SO}_{2}(\mathrm{~m} / \mathrm{z}$ 64). Distinctive changes are also seen on the profiles for $\mathrm{m} / \mathrm{z} 16,17$ and $\mathrm{m} / \mathrm{z} 28$ where after oxidation these species decompose in a low temperature range. This might be related to an increase in the level of oxidation of nitrogen functionalities. Interestingly, in the case of C-B a small decrease in the intensity of the $m / z 64$ thermal profile is noticed suggesting less sulfones on the surface. In the case of C-BO an opposite effect was found. Oxidation of surface and less sulfones can explain the decrease in the capacitance measured after wetting in sulfuric acid compared to the value measured in water. For C-A after sulfuric acid wetting a dramatic decrease in the intensity of the $m / z 28$ is found. For the initial sample this could be related to the oxidation of quinones, which are usually considered as a source Faradaic reaction. Analyzing this sample we have to take into account its small surface area, so even though the amount of some redox active groups could increase after wetting $(\mathrm{m} / \mathrm{z}$ 64), blocking of the small but still existing volume of pores, which could be initially active in EDLC, could result in about $50 \%$ decrease in the electrochemical capacitance after sulfuric acid wetting.

The thermal analysis results combined with mass spectra profiles are in good agreement with those from potentiometric titration experiments (Table 5). For all samples after sulfuric acid wetting an increase in the number of acidic groups is found. Interestingly, the average surface $\mathrm{pH}$ increased for all samples but C-AO (practically unchanged), which we link to decomposition of the strongest acidic groups, likely sulfonic acids. As a result of $\mathrm{H}_{2} \mathrm{SO}_{4}$ oxidation, oxygen 
containing acidic groups are formed on the surface and the results suggest that they are phenolic in their nature.

The surface oxidation during sulfuric acid wetting of the active carbon materials is also seen on the FTIR spectra (Figure 8). After wetting the intensity of the band related to $\mathrm{C}=\mathrm{O}$ vibrations increased, especially for C-AO sample. The effects of oxidation are especially visible for bands at $1720 \mathrm{~cm}^{-1}, 1560 \mathrm{~cm}^{-1}, 1070 \mathrm{~cm}^{-1}$ and $730 \mathrm{~cm}^{-1}$ which are characteristic of stretching vibrations of carbonyl functional groups band $\mathrm{C}=\mathrm{O}$ in carboxylic acids, conjugated carbonyl and carboxylate groups [48], C-O and $\mathrm{S}=\mathrm{O}$ from sulfonic groups [48, 49], respectively. The complex band at $1560 \mathrm{~cm}^{-1}$ can be also linked to amide groups [50].

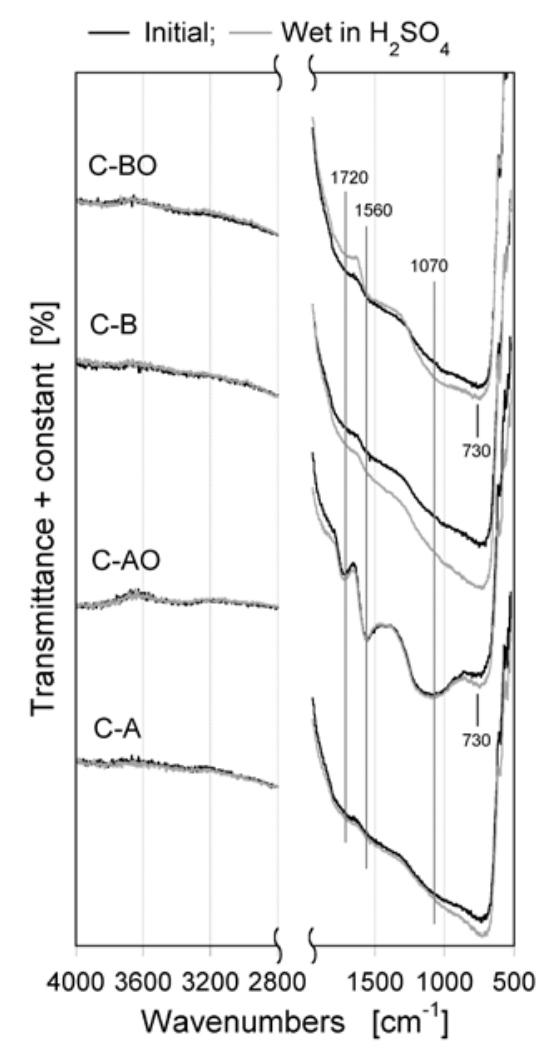

Figure 8. FTIR spectra for the initial and wetted in $1 \mathrm{M} \mathrm{H}_{2} \mathrm{SO}_{4}$ carbon samples. 
Support for the hypothesized above changes/limitations in the pores accessibility after $\mathrm{H}_{2} \mathrm{SO}_{4}$ wetting are the results of the porosity measurement. As seen from Table 1, the surface area accessible for nitrogen molecules decreased most drastically for the C-A and C-B initial samples after acid wetting. This is owing to the deposition of functional groups at the pore entrances, and/or collapsing of some pores, which results in a significant decrease in EDLC, even though that capacitance when the pores are accessible cannot be considered as high due to the very limited volume in small pores.

The presented above results addressed the surface chemistry of the active carbon component, not the one of the real electrodes. Taking into account how the electrode are made by grinding with the binder (10 wt. \%) and carbon black (10 wt. \%) the real surface of the electrode materials can differ from that of the active carbon components. Since the pronounced decreases in the performance after wetting are found for C-B and C-AO, the electrodes made of those samples were arbitrary chosen for the detailed analysis of their surface chemistry as a result of applied wetting. The contents of elements on the surface and the results of the deconvolution of the C 1 s, $\mathrm{O} 1 s, \mathrm{~N} 1 s$ and $\mathrm{S} 2 p$ are collected in Table S1-S5 of Supplementary information. The high content of fluorine is related to the presence of the PVDF as binder. It results in a decrease in the relative content of all elements, especially sulfur. After wetting of C-AOE either in water or in sulfuric acid, the total content of elements on the surface is not markedly changed. Nevertheless, an increase in the fluorine content with a stable content of other elements suggests a slight oxidative effect. This trend is in agreement with the TA/MS and potentiometric results and it is linked to the saturation of the active centers of this carbon with oxygen during air activation. More pronounced changes after wetting, consistent with the results of potentiometric titration 
and TG/MS are seen for the C-BE where the content of oxygen increased about $25 \%$ after wetting in acid. For this carbon the amount of acidic groups increased $26 \%$ (Table S1 of Supplementary Information). A decrease the content of nitrogen and an increase the content of sulfur are also noticed. Interestingly, the same trends but much less marked are seen after wetting this sample in water suggesting that even in water some oxidizing agents are present. These agents can be only $\mathrm{OH}$ radicals formed as a result of photoactivity of this carbon [51] since the experiments were done under ambient light.

Detailed information can be derived from the deconvolution of $\mathrm{C} 1 s, \mathrm{O} 1 s, \mathrm{~N} 1 s$ and $\mathrm{S} 2 p$ core energy levels (Figures 9 and 10). Based on C 1s, for C-AOE wetting in acid results in oxidation of some phenolic and alcoholic groups to carboxylic acids. For C-BE the reduction of oxygen in carboxylic acids, carbonyl and quinones is found with an increase in phenols, alcohols and etheric species. For C-BEa the presence of the high energy contribution at $293.5 \mathrm{eV}$ is found. This is a very specific contribution not detected in the other carbons and we link it to the presence of fluorine incorporated to the aromatic rings of the carbon matrix [52]. This suggests that the surface reactivity of C-B carbon in the presence of strong sulfuric acid is able to affect the chemistry of PVDF binder. Even though PVDF is commonly considered as very inert, the studies have been reported on the acceleration of its chemistry under certain conditions. Thus in the presence of lithiated graphite the hydrodefluorination of PVDF was reported which questioned its application as a binder for lithium batteries electrodes [53]. Defluorination of PVDF in the presence of amines has been also reported [54]. Therefore, it possible that in the complex system of the C-B carbon defluorinaton takes place and releases HF that in turn reacts with the edges of carbon layers. Support for this is the deconvolution of F $1 \mathrm{~s}$ core energy level 
for this sample which show two contributions: at $687.9 \mathrm{eV}(74.70 \%)$ and at $690.8 \mathrm{eV}(25.30 \%)$ (Figure S4 of Supplementary Information). While the first one is related to F-C bonds the second represents C-F in aromatic rings [55] 

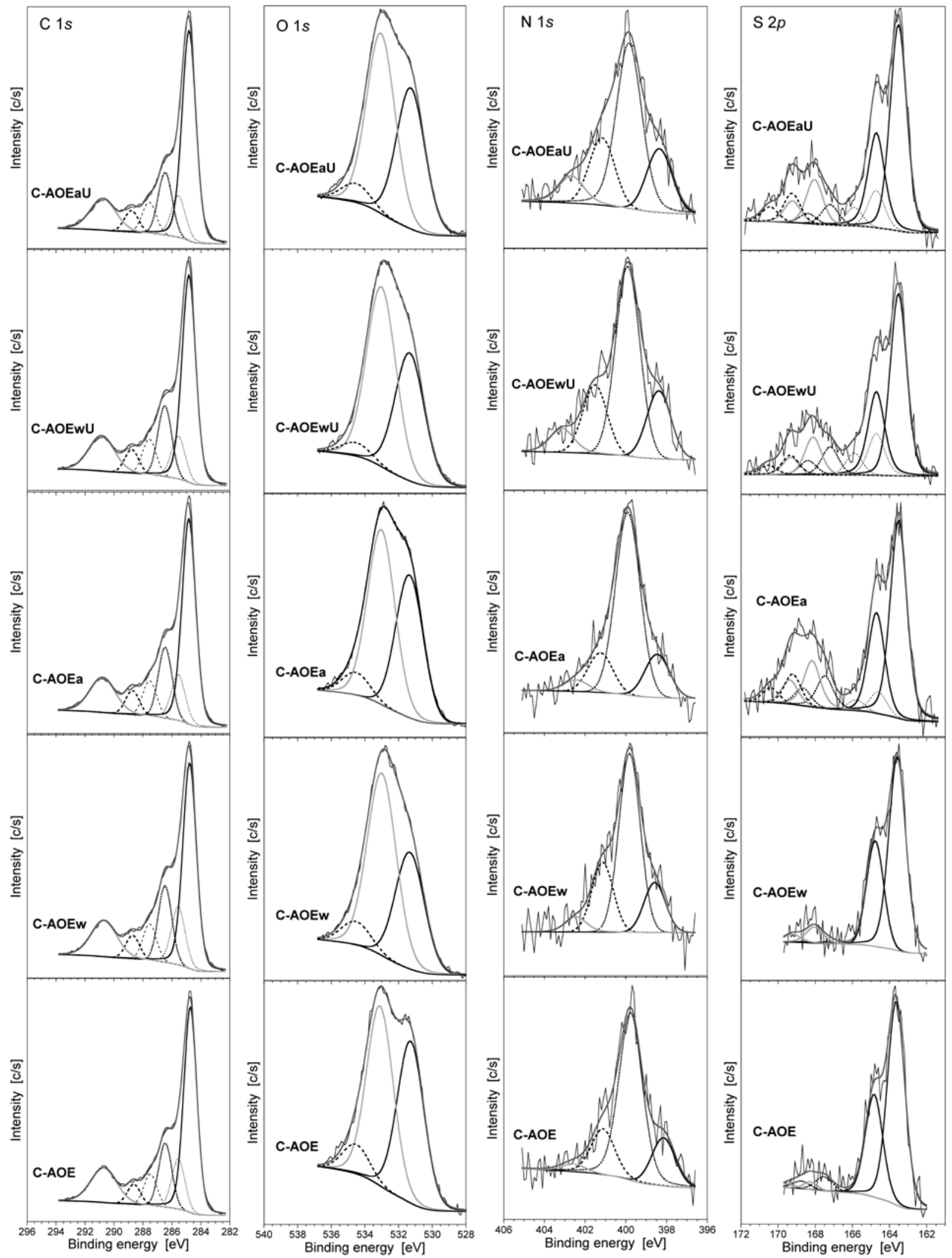

Figure 9. C $1 s, \mathrm{O} 1 s, \mathrm{~N} 1 s$ and S $2 p$ core energy levels for the air oxidized carbon (C-AO). 


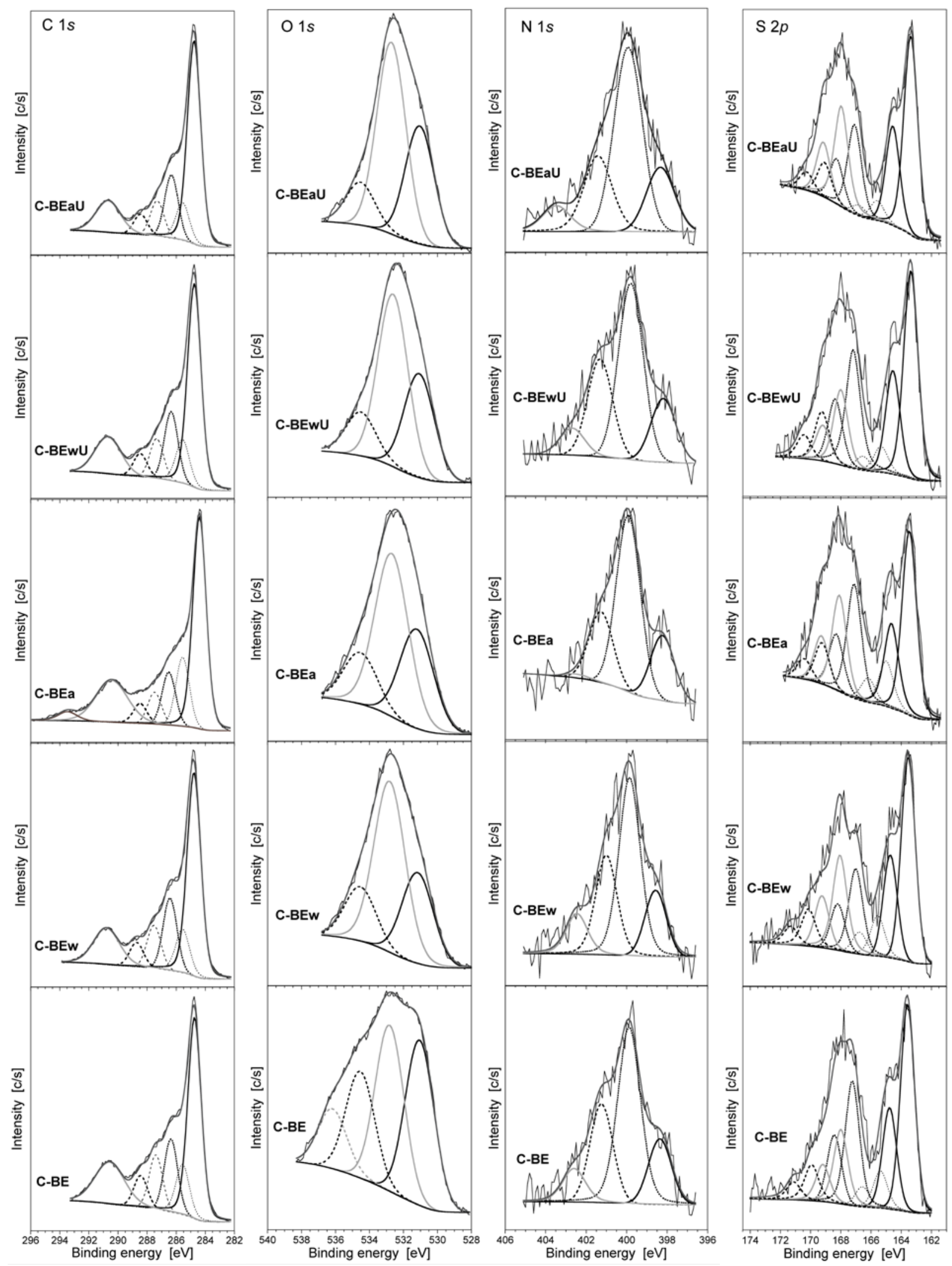

Figure 10. C 1s, O 1s, $\mathrm{N} 1 s$ and $\mathrm{S} 2 p$ core energy levels for the initial carbon (C-B). 
Changes in $\mathrm{O} 1 \mathrm{~s}$ for $\mathrm{C}-\mathrm{AOE}$ (Figure 9) suggest that both, acid and water wettings led to a decrease in the contribution of oxygen in carbonyls, ethers and sulfoxides/sulfones and an increase in phenolic/epoxy, thioethers and sulfonic groups. This indicates oxidation of sulfur species. Interestingly this effect is especially visible after wetting in water. This is supported by changes in S $2 p$ core energy level where a marked decrease in the contribution of sulfoxides/sulfones and an increase in sulfonic acids are found after water wetting. Wetting with sulfuric acid, on the other hand, significantly oxidizes thioles and bisulfides to sulfoxides and sulfonic acids. Moreover, $\mathrm{SO}_{4}{ }^{2-}$ ions should be present in the pore system as a result of their adsorption from electrolyte. The deconvolution of $\mathrm{O} 1 \mathrm{~s}$ core energy level also shows an increase in the contribution of sulfonic acids after acid wetting. Deconvolution on $\mathrm{N}$ 1s core energy level for C-AOE shows that after wetting in water protonation of amines occurs (an intensity decrease at $399.1 \mathrm{eV}$ and an intensity increase at $401.4 \mathrm{eV}$ [38]) accompanied by an increase in the contribution of pyridine N-oxide. Even though quaternary nitrogen has the binding energy the same as protonated amines [38], we do not expect an incorporation of more nitrogen into aromatic ring as a result of the treatment applied. The contribution of the protonated amines also increases after wetting with acid.

The deconvolution of $\mathrm{O} 1$ s core energy level for C-BE confirms the removal of some carboxylic acids and formation of a significant amount of phenols/epoxy, ethers and sulfonic groups on the surface (Figure 10). An important feature of C-BE, which is going to be discussed later, is the presence of a marked amount of oxygen adsorbed on the surface of this electrode. The deconvolution of S $2 p$ for C-BE shows that sulfur on the surface of this electrode is in much higher oxidation states than that on C-AOE. Nevertheless, the directions in the changes after wetting are the same as those for C-AOE. Thus water wetting oxidizes sulfones/sulfoxides to 
sulfonic acids and acid wetting attacks reduced sulfur in thioles and bisulfides and converts them to sulfonic acids. The amount of the sulfate ions originated from the electrolyte is smaller than that in the case of the C-AOE samples, owing to the smaller porosity. Even though the direction of changes in the oxidation level of nitrogen for C-BE species is similar to that found for CAOE, the wetting with acid brings much more dramatic changes, with almost all the pyridine-Noxides being eliminated in favor of an increase in pyridine and pyrrolic/pyridone nitrogen. The former likely occurred through oxidative destruction. A significant finding from the above analysis is that not only sulfuric acid but also water wetting results in the oxidation of the carbon surface and sulfur functionalities are the most susceptible to oxidation surface species. As mentioned above, the presence of the oxidizing agents in water might be linked to the photoactivity of the carbons studied. When carbon containing only sulfur was investigated, that photoactivity was linked to the sulfur in aromatic rings modifying the band gap of the carbons $[28,56]$.

\subsection{Analysis of photoactivity}

Following the presence of that photoactivity effect and to further investigate the small but consistent increase in the capacitance after VL irradiation, the chronoamperometry experiments were run at constant bias potential values in dark and under VL irradiation. The examples of the results obtained are presented in Figure 11. As seen, VL irradiation visibly increases the cathodic current measured. Since this effect was not observed in the absence of oxygen, we link it to oxygen reduction process on the surface of our electrodes [40,41]. The comparison of the photocurrent densities generated on our polymer-derived carbon electrodes after wetting in water and sulfuric acid are presented in Figure 11. To ensure that neither the titanium foil nor the 
solvent are playing a role in the observed photoactivity, the same experiments were carried out on the titanium foil and on Ti foil with the N-methyl-2-pyrrolidone solvent. While the solvent did not show any activity, the Ti foil pasted with 10 wt. \% binder and 90 wt. \% carbon black generated a very small current started at potential below $0 \mathrm{~V}$ vs. $\mathrm{Ag} / \mathrm{AgCl}$ (Figure S5 of Supporting Information) and it clearly shows that the origin of the VL effect is only in the carbon surface. The photocurrent was recorded in the potential range of $0.6 \mathrm{~V}$ and $-0.2 \mathrm{~V}$, with the exception of carbon sample C-B (after wetting in sulfuric acid), which was measured only at $0.12 \mathrm{~V}$ (Figure 6). This potential $(0.12 \mathrm{~V})$ was selected for being the most photoactive within the potential window of $0.6 \mathrm{~V}$ to $-0.2 \mathrm{~V}$ vs. Ag/AgCl. The C-B sample demonstrated a broad peak at this potential. After wetting in water the order of a decreasing photocurrent is the following C-A $>\mathrm{C}-\mathrm{B}>\mathrm{C}-\mathrm{AO}=\mathrm{C}-\mathrm{BO}$. Sulfuric acid wetting changes the order to: $\mathrm{C}-\mathrm{B}>\mathrm{C}-\mathrm{AO}=\mathrm{C}-\mathrm{BO}>\mathrm{C}-\mathrm{A}$. Neutral wetting obviously shows the C-A sample as one with the most photoactive surface and we link it to the high content of sulfonic acids/sulfoxides and sulfones either in the active carbon materials or in the electrode.

To have a closer look on the origin of the activity of carbons the detailed XPS study of the CAOE and C-BE electrodes after wetting in water or sulfuric acid and used for chronoamperometry in dark and under solar light irradiation was carried out. The results are collected in Tables S1-S5 of Supplementary Information and Figures 9 and 10. The deconvolution of $\mathrm{C} 1 \mathrm{~s}$ core energy level suggests that the most extensive changes toward reduction of the surface are seen for the sample wetted in sulfuric acid. The reduction of surface species is also confirmed in the deconvolution results of the $\mathrm{O} 1 \mathrm{~s}$ spectra. On the other hand, the deconvolution of S $2 p$ core energy level brings much more complex results. While for C- 
AOEwU wetted in water a marked oxidation of the surface is found, the sample wetted in sulfuric acid, C-AOEaU reveals the signs of reduction of oxysulfur compounds to sulfides and thioethers. Totally opposite trend is found for C-BEaU. On its surface the amount of highly reduced and highly oxidized sulfur species increased with the decrease of sulfur on intermediate level of oxidation. For C-BEwU the visible decreases in sulfides/thioethers and sulfonic acids is found with an increase in sulfoxides/sulfones. In the case of the surface nitrogen species more contribution of pyridine and pyridine $-\mathrm{N}$ oxide is found for carbons after the chronoamperometry experiment on C-AOE. For C-BE mixed effects were detected with no established trend.

These complex changes suggest the involvement of sulfur and nitrogen compounds in the light promoted reduction of oxygen. One mechanism leading to it might be related to the photogeneration of electron-hole pairs [57] is a result of the decrease the band gap owing to the presence of heteroatoms and disturbance in $\pi-\pi$ orbitals of the carbons matrix [56, 58]. They might enhance catalytic oxygen reduction and also result in the reductive changes observed on the surface. Formation of holes could be responsible for oxidation of some surface compounds. The complex effects might be the apparent results of this photoactivity. Another mechanism of photoactivity and enhanced oxygen reduction in the presence of light might be related to the presence of sulfur-oxygen organic moieties and nitrogen compounds. Such species are known to be chromophores [59]. Thus upon expose to light, the electrons in the active parts of those functional groups might get excited and instead of returning to the ground state and due to the fact that this happen in the cathodic range, they are rather accepted by molecular oxygen existing in the pore system. In this way the charged superoxide ions are formed and they increase the apparent capacitance. This process might be responsible for the reduction of the chromophores 
and the XPS results suggest that sulfur-oxygen containing groups are those acting as chromophores moieties.

The very high activity for oxygen reduction was found on C-B carbon which have some small pores where oxygen can be adsorbed and a broad distribution of sulfur species. Supporting for this is also the detection of relatively high contribution of molecular oxygen on the surface of this carbon. The molecular oxygen, when converted to superoxide ion in ORR as a result of catalytic/photocatalyic activity, might be responsible for the marked oxidation of reduced sulfur species on the surface of this carbon even after water wetting.
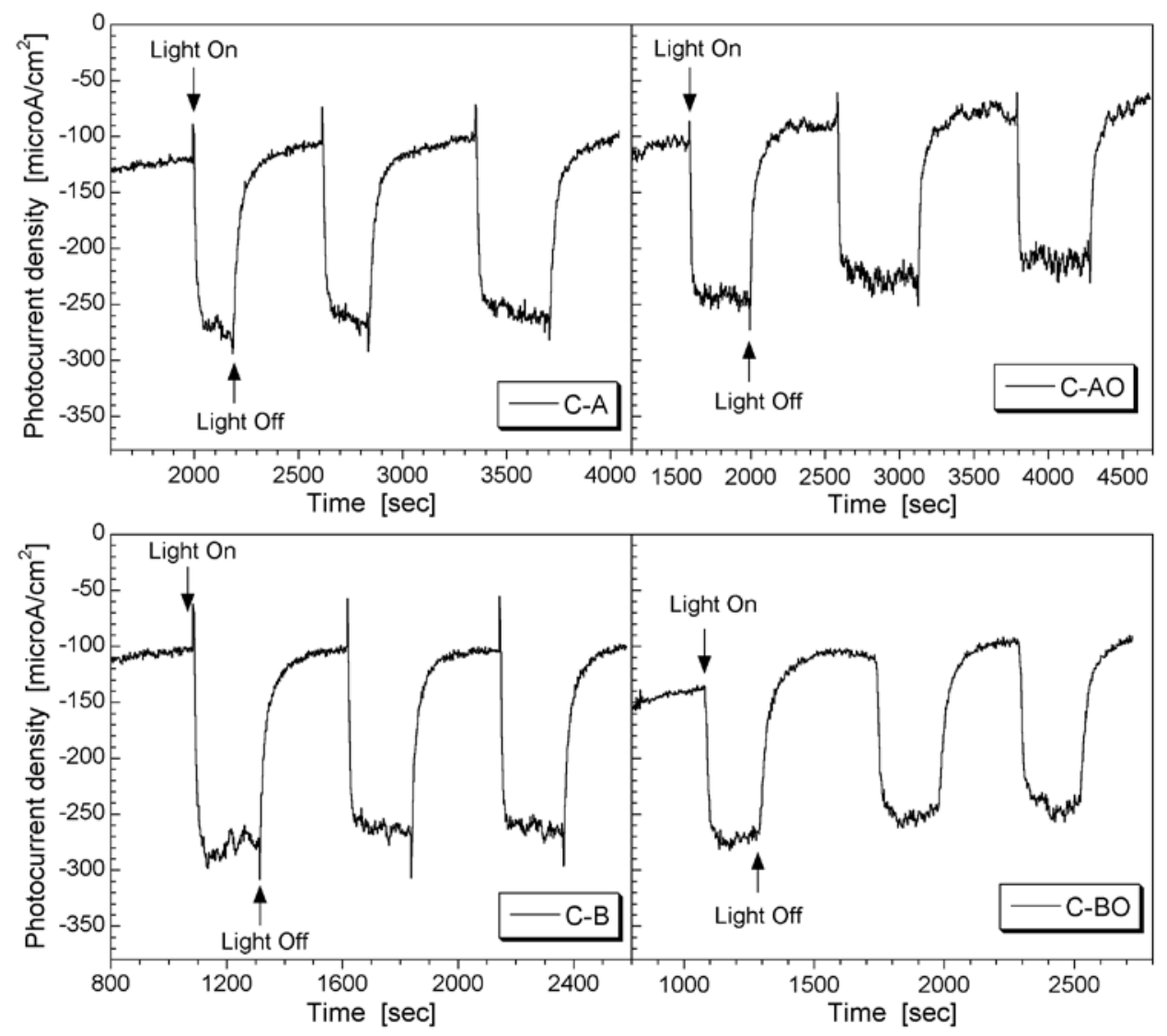

Figure 11. Examples of current signals in dark and under solar light irradiation at $-0.2 \mathrm{~V}$ vs. $\mathrm{Ag} / \mathrm{AgCl}$ for the carbon materials prior wetted in water. 


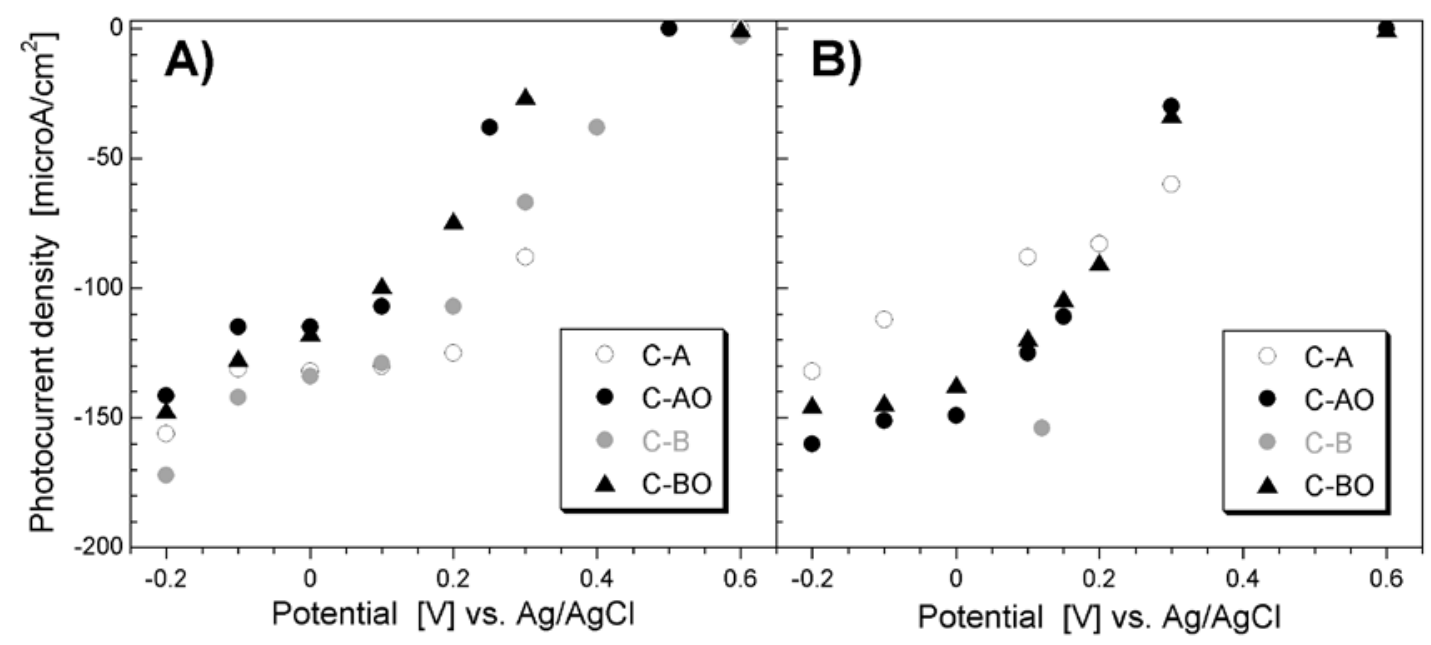

Figure 12. Photocurrent response at various bias potentials after wetting in water (A) and in sulfuric acid (B). For the C-B sample after wetting in sulfuric acid photocurrent was measured only at the potential $0.12 \mathrm{~V}$ vs. Ag/AgCl. At lower potential, owing to the photoactivity of this sample the surface chemistry changed (see Figure 6).

Photocurrent generated in chronoamperometry experiments might have an effect on the capacitive behavior owing the changes in surface chemistry, which accompany this process. Therefore the CV curves were measured again using the same working electrodes, which were tested for VL photocurrent generation. The measured capacitance values are collected in Table 4. As seen, for C-A after wetting either in water or sulfuric acid, and for C-B wetted in sulfuric acid, the capacitance increased significantly. The measured current was high on these materials, and as suggested by the initial capacitance measurement and by the chemical analysis of the surface, sulfuric acid wetting resulted in carbon oxidation. This process limited the access of the electrolyte ion to the small pores owing to the formation of new surface groups. Obviously, during the electrochemical measurements, reduction of the newly formed species and the sulfur species (sulfonic acid) existing initially on the surfaces led to the opening of pores for EDLC, 
creation of more electrochemically active species (such as sulfones or sulfoxides) and attraction of more sulfate ions via positive charge on the carbon surface imposed by the presence of reduced sulfur compounds increased the capacitance. The positive charge can also be imposed by nitrogen incorporated to the carbon matrix in pyridine-N-oxide configurations [21, 22]. These species may not only attract anions but they also promote a fast electron transfer [21, 22].

\section{Conclusions}

The results presented in this paper show the paramount role of surface chemistry associated with sulfur and nitrogen containing groups for the capacitive behavior of nanoporous carbons. As shown, the carbons with the low surface area and porosity reach the capacitance of $450 \mathrm{~F} / \mathrm{g}$. On practically nonporous carbon the capacitance of about $100 \mathrm{~F} / \mathrm{g}$ was measured. It is linked to the richness of surface chemistry and the presence of sulfur, nitrogen, and oxygen containing groups, which might undergo reversible Faradaic reactions. Owing to the presence of heteroatoms the apparent band gap on the carbons decreased leading to the photogeneration of electron-hole pairs. While electrons contributed to the oxygen reduction, the latter oxidized some sulfur containing groups on the carbon surface. The sulfur containing groups, especially sulfoxides/sulfones and sulfonic acids were also found as acting as chromophores moieties, which can increase the electrochemical capacitance of carbon. Excited by light electrons are proposed to participate in oxygen reduction reactions. This process leads to the reduction of chromophoric groups, which, on the other hand, have a positive effect of the capacitance increasing the pore accessibility and the degree of pore volume utilization. Without the effect of visible light oxygen is reduced as a result of the catalytic properties of the carbon. The results showed that the pre-measurement wetting can have a pronounced effect on the capacitive behavior of carbons. This is not only 
owing to a complete surface accessibility by ions (increase) but also owing to the surface reactivity and its vulnerability to oxidation (mixed effects).

\section{ACKNOWLEDGMENT}

The support of the Australian Research Council (DP110101293) and the Centre of Advanced Nanomaterials of The University of Adelaide is also gratefully acknowledged. The authors are grateful to Mr. Saeid Sedghizeinolhajloo for his help in converting XPS data files. The Australian Microscopy and Microanalysis Research Facility (AMMRF) is gratefully acknowledged for access to the Kratos Axis-Ultra XPS instrument. 


\section{References}

1. Burke A. R\&D considerations for the performance and application of electrochemical capacitors. Electrochimica Acta 2007;53:1083-91.

2. Heon M, Lofland S, Applegate J, Nolte R, Cortes E, Hettinger JD, et al. Continuous carbide-derived carbon films with high volumetric capacitance. Energy Environ Sci 2011;4:135-8.

3. Itoi H, Nishihara H, Kogure T, Kyotani T. Three-dimensionally arrayed and mutually connected 1.2-nm nanopores for high-performance electric double layer capacitor. J Am Chem Soc 2011;133: 1165-7.

4. Hasegawa G, Aoki M, Kanamori K, Nakanishi K, Hanada T, Tadanaga K. Monolithic electrode for electric double-layer capacitors based on macro/meso/microporous S-containing activated carbon with high surface area. J Mater Chem 2011;21: 2060-3.

5. Wang D, Li F, Liu M, Lu GQ, Cheng HM. 3D Aperiodic hierarchical porous graphitic carbon material for high-rate electrochemical capacitive energy storage. Angew Chem Int 2008;47:373-6.

6. Pandolfo AG, Hollenkamp AF. Carbon properties and their role in supercapacitors. J. Power Sources 2006;157:11-27.

7. Simon P, Gogotsi Y. Capacitive energy storage in nanostructured carbon-electrolyte systems. Acc Chem Res 2013;46:1094-103.

8. Seredych M, Bandosz TJ. S-doped micro/mesoporous carbon/graphene composites as efficient supercapacitors in alkaline media. J Mater Chem A 2013;1:11717-27.

9. Sassin MB, Chervin CN, Rolison DR, Long JW. Redox deposition of nanoscale metal oxides on carbon for next-generation electrochemical capacitors. Acc Chem Res 2013;46:1062-74. 
10. Zhao X, Sanchez BM, Dobson PJ, Grant PS. The role of nanomaterials in redox-based supercapacitors for next generation energy storage devices. Nanoscale 2011;3:839-55.

11. Zheng JP, Cygan PJ, Jow TR. Hydrous ruthenium oxide as an electrode material for electrochemical capacitors. J Electrochem Soc 1995;142:2699-703.

12. Seredych M, Bandosz TJ. Evaluation of $\mathrm{GO} / \mathrm{MnO}_{2}$ composites as supercapacitors in neutral electrolytes: role of graphite oxide oxidation level. J Mater Chem 2012;22:23525-33.

13. Salitra G, Soffer A, Eliad L, Cohen Y, Aurbach D. Carbon electrodes for double-layer capacitors I. Relations between ion and pore dimensions. J Electrochem Soc 2000;147:248693.

14. Chmiola J, Yushin G, Gogotsi Y, Portet C, Simon P, Taberna P.L. Anomalous increase in carbon capacitance at pore sizes less than 1 nanometer. Science 2006;313:1760-3.

15. Largeot C, Portet C, Chmiola J, Taberna PL, Gogotsi Y, Simon P. Relation between the ion size and pore size for an electric double-layer capacitor. J Am Chem Soc 2008;130:2730-1.

16. Andreas HA, Conway BE. Examination of the double-layer capacitance of an high specificarea C-cloth electrode as titrated from acidic to alkaline pHs. Electrochimica Acta 2006;51:6510-20.

17. Seredych M, Koscinski M, Sliwinska-Bartkowiak M, Bandosz TJ. Charge storage accessibility factor as a parameter determining the capacitive performance of nanoporous carbon-based supercapacitors. ACS Sustainable Chem Eng 2013;1:1024-32.

18. Hulicova-Jurcakova D, Seredych M, Lu GQ, Bandosz TJ. Specific anion and cation capacitance in porous carbon blacks. Carbon 2010;48:1767-78. 
19. Gomez H, Ram MK, Alvi F, Villalba P, Stafanakos E, Kumar A. Graphene-conducting polymer nanocomposite as novel electrode for supercapacitors. J Power Sources 2011;196:4102-8.

20. Seredych M, Koscinski M, Sliwinska-Bartkowiak M, Bandosz TJ. Active pore space utilization in nanoporous carbon-based supercapacitors: Effects of conductivity and pore accessibility. J Power Sour 2012;220:243-52.

21. Wang D-W, Li F, Yin L-C, Lu X, Chen Z-G, Gentle IR, et al. Nitrogen-doped carbon monolith for alkaline supercapacitors and understanding nitrogen-induced redox transitions. Chem Eur J 2012;18:5345-51.

22. Hulicova-Jurcakova D, Seredych M, Lu GQ, Bandosz TJ. Combined effect of nitrogen- and oxygen-containing functional groups of microporous activated carbon on its electrochemical performance in supercapacitors. Adv Funct Mat 2009;19:438-47.

23. Hulicova-Jurcakova D, Puziy AM, Poddubnaya OI, Suarez-García F, Tascon JMD, Lu GQ. Highly stable performance of supercapacitors from phosphorus-enriched carbons. J Am Chem Soc 2009;131:5026-7.

24. Zhao X, Zhang Q, Chen C-M, Zhang B, Reiche S, Wang A, et al. Aromatic sulfide, sulfoxide, and sulfone mediated mesoporous carbon monolith for use in supercapacitor. Nano Energy 2012;1:624-30.

25. Seredych M, Singh K, Bandosz TJ. Insight into the capacitive performance of sulfur-doped nanoporous carbons modified by addition of graphene phase. Electroanalysis 2014;26: 10920. 
26. Liang J, Jiao Y, Jaroniec M, Qiao SZ. Sulfur and nitrogen dual-doped mesoporous graphene electrocatalyst for oxygen reduction with synergistically enhanced performance. Angew Chem Int Ed 2012;51:1-6; Angew Chem 2012;124:11664-8.

27. Seredych M, Idrobo J-C, Bandosz TJ. Effect of confined space reduction of graphite oxide followed by sulfur doping on oxygen reduction reaction in neutral electrolyte. J Mater Chem A 2013;1:7059-67.

28. Bandosz TJ, Matos J, Seredych M, Islam MSZ, Alfano R. Photoactivity of S-doped nanoporous activated carbons: A new perspective for harvesting solar energy on carbonbased semiconductors. Appl Catal A: Gen 2012;445-446:159-65.

29. Seredych M, Bandosz TJ. Confined space reduced graphite oxide doped with sulfur as metalfree oxygen reduction catalyst. Carbon 2014;66:227-33.

30. Jagiello J, Olivier JP. A simple two-dimensional NLDFT model of gas adsorption in finite carbon pores. Application to pore structure analysis. J Phys Chem C 2009;113:19382-5.

31. Skinner WM, Prestidge CA, Smart RSC. Irradiation effects during X-ray photoelectron spectroscopy studies of copper (II) activated zinc sulfide. Surf Interface Anal 1996;24:620-6.

32. von Oertzen GU, Skinner WM, Nesbitt HW, Pratt AR, Buckley AN. Cu adsorption on pyrite (100): Ab initio and spectroscopic study. Surf Sci 2007;601:5794-9.

33. Jagiello J. Stable numerical solution of the adsorption integral equation using splines. Langmuir 1994;10:2778-85.

34. Jagiello J, Bandosz TJ, Schwarz JA. Carbon surface characterization in terms of its acidity constant distribution. Carbon 1994;32:1026-8. 
35. Seredych M, Hulicova-Jurcakova D, Lu GQ, Bandosz TJ. Surface functional groups of carbons and the effects of their chemical character density and accessibility to ions on electrochemical performance. Carbon 2008;46:1475-88.

36. Figueiredo JL, Pereira MFR, Freitas MMA, Órfão JJM. Modification of the surface chemistry of activated carbons. Carbon 1999;37:1379-89.

37. Herrera-Alonso M, Abdala AA, McAllister MJ, Aksay IA, Prud’homme RK. Intercalation and stitching of graphite oxide with diaminoalkanes. Langmuir 2007;23:10644-9.

38. Pels JR, Kapteijn F, Moulijn JA, Zhu Q, Thomas KM. Evolution of nitrogen functionalities in carbonaceous materials during pyrolysis. Carbon 1995;33:1641-53.

39. Huh SH. Thermal reduction of graphene oxide. In: Mikhailov S, editor. Physics and applications of graphene - experiments, InTech; 2011 p. 73-90.

40. Kwon K, Sa YJ, Cheon JY, Joo SH. Ordered mesoporous carbon nitrides with graphitic frameworks as metal-free, highly durable, methanol-tolerant oxygen reduction catalysts in an acidic medium. Langmuir 2012;28:991-6.

41. Yu D, Zhang Q, Dai L. Highly efficient metal-free growth of nitrogen-doped single-walled carbon nanotubes on plasma-etched substrates for oxygen reduction. J Am Chem Soc 2010;132:15127-9.

42. Ma F, Zhao H, Sun L, Li Q, Huo L, Xia T, et al. A facile route for nitrogen-doped hollow graphitic carbon spheres with superior performance in supercapacitors. J Mater Chem 2012;22:13464-8.

43. Kim ND, Kim W, Joo JB, Oh S, Kim P, Kim Y, et al. Electrochemical capacitor performance of N-doped mesoporous carbons prepared by ammoxidation. J Power Sour 2008;180:671-5. 
44. Tsubota T, Takenaka K, Murakami N, Ohno T. Performance of nitrogen- and sulfurcontaining carbon material derived from thiourea and formaldehyde as electrochemical capacitor. J Power Sour 2011;196:10455-60.

45. Zhang D, Zheng L, Ma Y, Lei L, Li Q, Li Y, et al. Synthesis of nitrogen- and sulfur-codoped 3D cubic-ordered mesoporous carbon with superior performance in supercapacitors. ACS Appl Mater Interfaces 2014;6:2657-65.

46. Si W, Zhou J, Zhang S, Li S, Xing W, Zhuo S. Tunable N-doped or dual N, S-doped activated hydrothermal carbons derived from human hair and glucose for supercapacitor applications. Electrochimica Acta 2013;107:397-405.

47. Endo M, Maeda T, Takeda T, Kim YJ, Koshiba K, Hara H, Dresselhaus MS. Capacitance and pore-size distribution in aqueous and nonaqueous electrolytes using various activated carbon electrodes. J Electrochem Soc 2001;148:A910-4.

48. Zawadzki J. IR spectroscopy in carbon surface chemistry. In: Thrower PA, editor. Chemistry and physics of carbon, vol 21, New York; Dekker; 1989 p. 180-200.

49. Bohner U, Zundel G. Proton potentials and proton polarizability of hydrogen bonds in sulfonic acid-oxygen base systems as a funtion of the $\Delta \mathrm{pK}_{\mathrm{a}}$. J Phys Chem 1985;89:1408-13.

50. Ko YG, Sung BH, Choi US. Electrorheological properties of aminated chitosans. Colloids Surf A 2007;305:120-5.

51. Velasco LF, Maurino V, Laurenti E, Fonseca IM, Lima JC, Ania C. Photoinduced reactions occurring on activated carbons. A combined photooxidation and ESR study. Appl Catal A: Gen 2013;452:1-8.

52. Mackie NM, Castner DG, Fisher ER. Characterization of pulsed-plasma-polymerized aromatic films. Langmuir 1998;14:1227-35. 
53. Zhang SS, Jow TR. Study of poly(acrylonitrile-methyl methacrylate) as binder for graphite anode and $\mathrm{LiMn}_{2} \mathrm{O}_{4}$ cathode of Li-ion batteries. J Power Sour 2002;109:422-6.

54. Taguet A, Ameduri B, Boutevin B. Crosslinking of vinylidene fluoride containing fluoropolymers. Adv Polym Sci 2005;184:127-211.

55. Briggs D, Seah MP. Practical Surface Analysis: Auger and X-ray Photoelectron Spectroscopy. 2nd ed. New York: John Wiley; 1990.

56. Strelko VV, Kuts VS, Thrower PA. On the mechanism of possible influence of heteroatoms of nitrogen, boron and phosphorus in a carbon matrix on the catalytic activity of carbons in electron transfer reactions. Carbon 2000;38:1499-503.

57. Xie G, Zhang K, Guo B, Liu Q, Fang L, Gong JR. Graphene-based materials for hydrogen generation from light-driven water splitting. Adv Mater 2013;25:3820-39.

58. Strelko VV, Kartel NT, Dukhno IN, Kuts VS, Clarkson RB, Odintsov BM. Mechanism of reductive oxygen adsorption on active carbons with various surface chemistry. Surf Sci 2004;548:281-90.

59. Beecher JE, Durst T, Fréchet JMJ, Godt A, Pangborn A, Robello DR, et al. New chromophores containing sulfonamide, sulfonate, or sulfoximide groups for second harmonic generation. Adv Mater 1993;5:632-4. 


\section{Captions to the Tables}

Table 1. The parameters of porous structure calculated from nitrogen adsorption isotherms.

Table 2. Content of elements on the surface (in at. \% from XPS analysis).

Table 3. The results of deconvolution of C $1 s, \mathrm{O} 1 s, \mathrm{~N} 1 s$ and S $2 p$ core energy levels.

Table 4. The specific capacitance values (in F/g) measured after wetting in water or sulfuric acid in dark or under visible light before and after chronoamperometry response upon on/off illumination.

Table 5. Potentiometric titration results. The number of groups in $\mathrm{mmol} / \mathrm{g}$ at each $\mathrm{pH}$ values is given in parenthesis. 


\section{Captions to the Figures}

Figure 1. N $1 s$ and S $2 p$ core energy levels.

Figure 2. TA and mass spectra thermal profiles for the C-A series of carbons. A) - initial, B) after wetting in sulfuric acid (multiplication factor: MW-16 x 7; MW-17 x 3; MW-18 x 1; MW28 x 1; MW-44 x 5; MW-48 x 50; MW-64 x 11).

Figure 3. TA and mass spectra thermal profiles for the C-B series of carbons. A) - initial, B) after wetting in sulfuric acid (multiplication factor: MW-16 x 7; MW-17 x 3; MW-18 x 1; MW28 x 1; MW-44 x 5; MW-48 x 50; MW-64 x 11).

Figure 4. A) X-Ray diffraction patterns and B) Raman spectra.

Figure 5. HR-TEM images.

Figure 6. The CV curves measured after wetting in water (A) and in sulfuric acid (B) at the scan rate of $5 \mathrm{mV} / \mathrm{s}$ in dark - D and under visible light - VL exposure.

Figure 7. Dependence of the specific capacitance on the number of acidic groups present on the carbon surface.

Figure 8. FTIR spectra for the initial and wetted in $1 \mathrm{M} \mathrm{H}_{2} \mathrm{SO}_{4}$ carbon samples.

Figure 9. C 1s, O 1s, N 1s and S $2 p$ core energy levels for the air oxidized carbon (C-AO).

Figure 10. C 1s, O 1s, N 1s and S $2 p$ core energy levels for the initial carbon (C-B).

Figure 11. Examples of current signals in dark and under solar light irradiation at $-0.2 \mathrm{~V}$ vs. $\mathrm{Ag} / \mathrm{AgCl}$ for the carbon materials prior wetted in water.

Figure 12. Photocurrent response at various bias potentials after wetting in water (A) and in sulfuric acid (B). For the C-B sample after wetting in sulfuric acid photocurrent was measured only at the potential $0.12 \mathrm{~V}$ vs. Ag/AgCl. At lower potential, owing to the photoactivity of this sample the surface chemistry changed (see Figure 6). 


\section{Effect of visible light and electrode wetting on the capacitive performance of S- and N-doped nanoporous carbons: Importance of surface chemistry}

Mykola Seredych ${ }^{1}$, Enrique Rodríguez-Castellón ${ }^{2}$, Mark Biggs ${ }^{3}$, William Skinner ${ }^{4}$ and Teresa J. Bandosz $z^{1 *}$

${ }^{1}$ Department of Chemistry, The City College of New York, 160 Convent Ave, New York, NY, 10031, USA.

${ }^{2}$ Departamento de Química Inorgánica, Universidad de Málaga, Spain.

${ }^{3}$ School of Chemical Engineering, The University of Adelaide, Adelaide, SA 5005, Australia.

${ }^{4}$ Ian Wark Research Institute, The ARC Special Research Centre for Particle and Material Interfaces, University of South Australia, Mawson Lakes, Adelaide, SA 5095, Australia.

*Corresponding author. Tel: (212) 650-6017; Fax: (212) 650-6107; E-mail address: tbandosz@ccny.cuny.edu (T.J. Bandosz) 


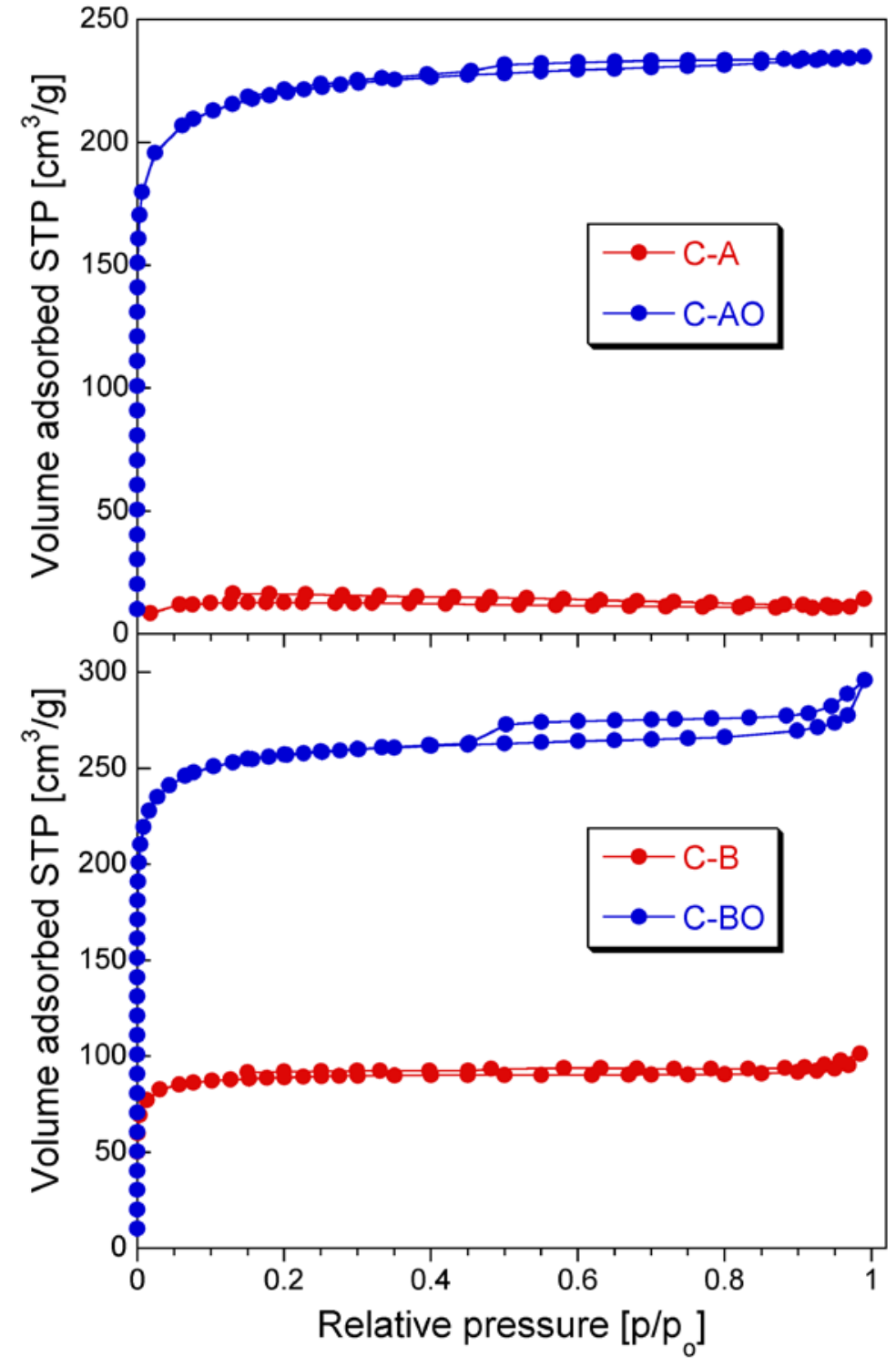

Figure S1. Nitrogen adsorption-desorption isotherms. 


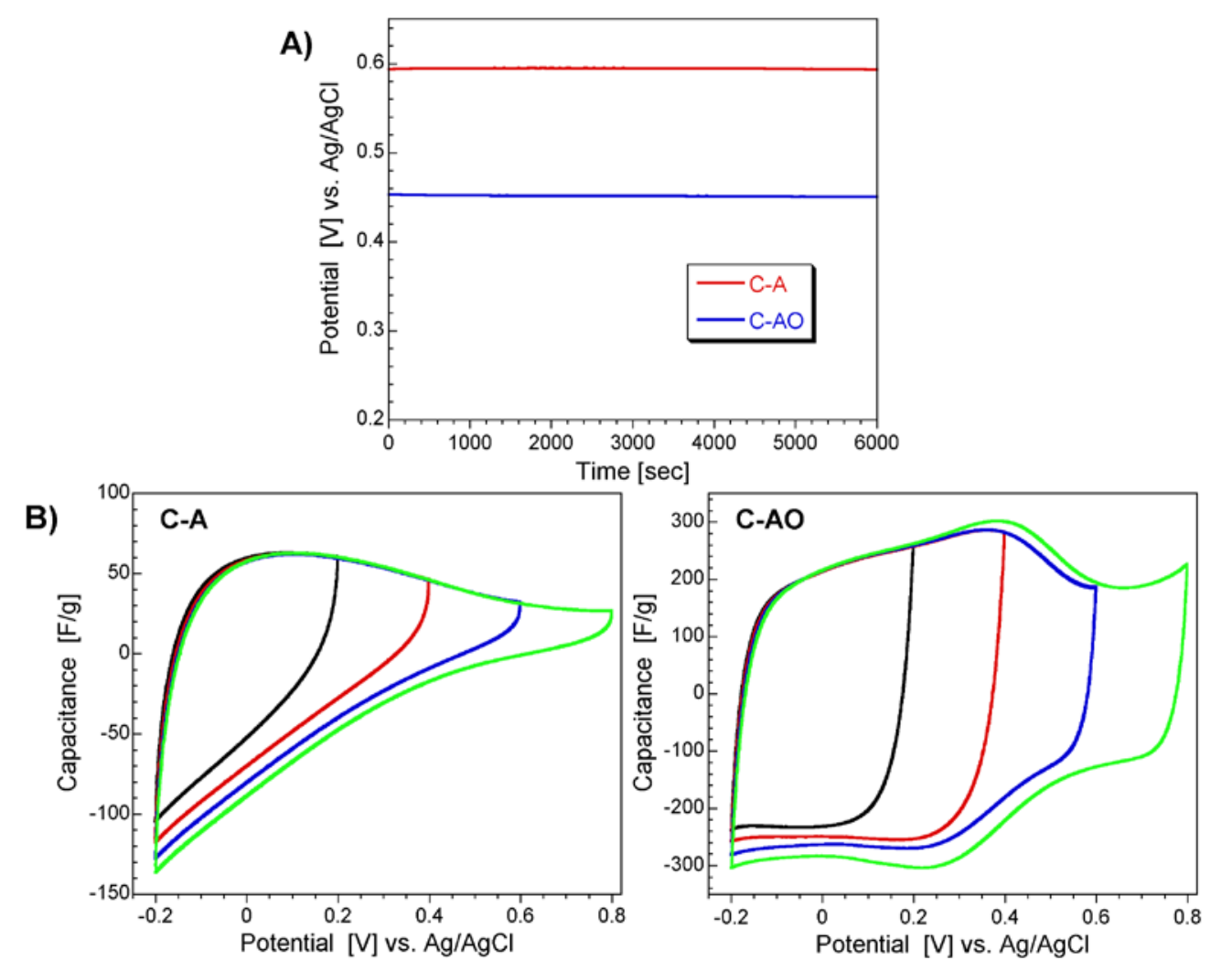

Figure S2. A) Open circuit potential and B) Cyclic voltammetry with gradual increase of the potential range after wetting in water 72 hours. 


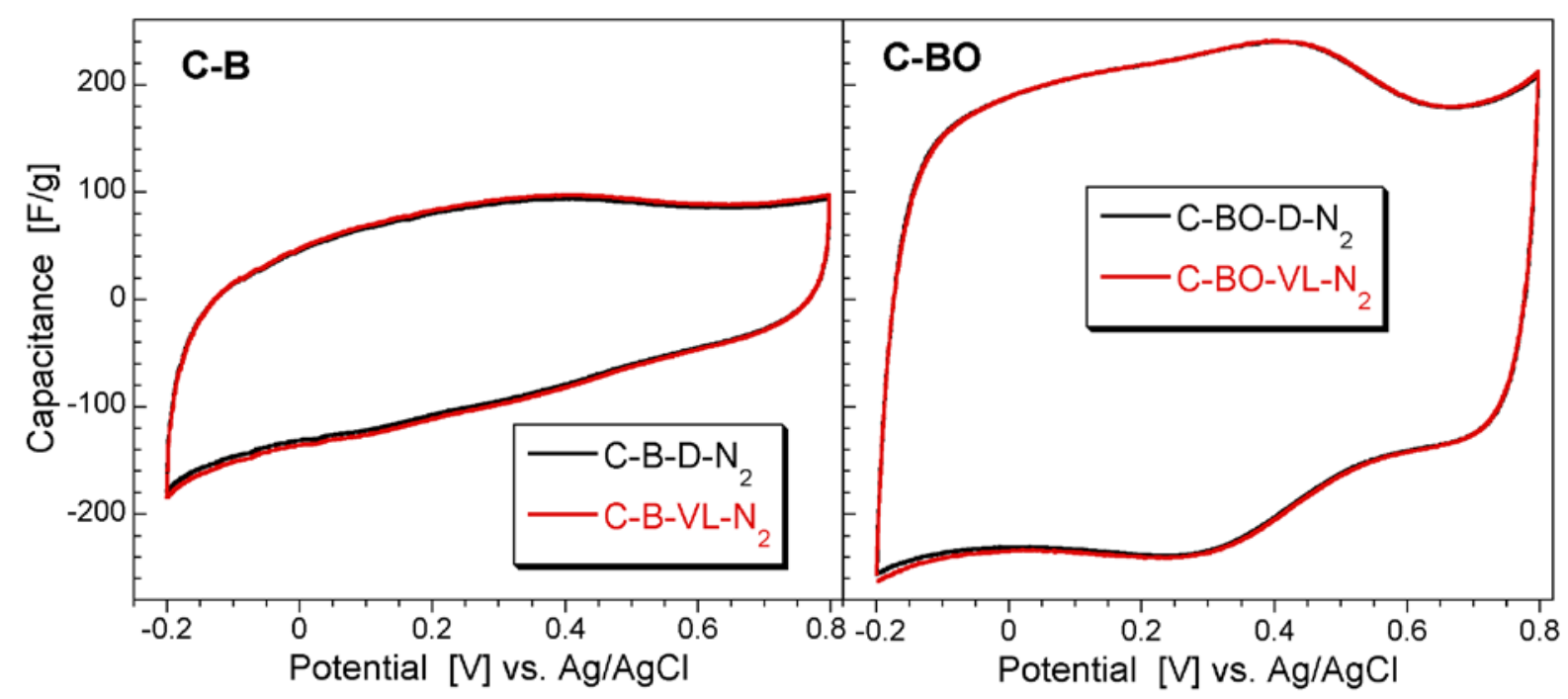

Figure S3. Cyclic voltammetry for non-oxidized and air oxidized carbon samples after wetting in $1 \mathrm{M} \mathrm{H}_{2} \mathrm{SO}_{4}$ without oxygen in the system in dark and under VL conditions.

Table S1. Content of elements on the surface (in at. \% from XPS analysis).

\begin{tabular}{lcccccc}
\hline Sample & $\mathrm{C}$ & $\mathrm{F}$ & $\mathrm{O}$ & $\mathrm{N}$ & $\mathrm{S}$ & $\mathrm{O} / \mathrm{C}$ \\
C-AOE & 72.3 & 14.3 & 12.0 & 1.1 & 0.2 & 0.166 \\
C-AOEw & 69.8 & 16.7 & 12.4 & 0.9 & 0.3 & 0.178 \\
C-AOEa & 69.5 & 17.0 & 12.0 & 1.2 & 0.3 & 0.173 \\
C-AOEwU & 69.8 & 17.1 & 12.0 & 0.9 & 0.3 & 0.172 \\
C-AOEaU & 69.4 & 17.4 & 12.1 & 1.0 & 0.2 & 0.174 \\
\hline C-BE & 68.7 & 21.1 & 8.1 & 1.7 & 0.4 & 0.118 \\
C-BEw & 68.4 & 20.4 & 9.3 & 1.3 & 0.5 & 0.136 \\
C-BEa & 66.5 & 21.4 & 10.5 & 1.1 & 0.6 & 0.158 \\
C-BEwU & 67.3 & 23.1 & 7.3 & 1.5 & 0.8 & 0.109 \\
C-BEaU & 68.5 & 18.0 & 11.0 & 1.7 & 0.8 & 0.161 \\
\hline
\end{tabular}


Table S2. The results of deconvolution of C 1s core energy level and their binding energy.

\begin{tabular}{lccccccc}
\hline Sample & $284.8 \mathrm{eV}$ & $285.6 \mathrm{eV}$ & $286.5 \mathrm{eV}$ & $287.5 \mathrm{eV}$ & $288.7 \mathrm{eV}$ & $290.7 \mathrm{eV}$ & $293.5 \mathrm{eV}$ \\
\hline C-AOE & 48.13 & 11.30 & 13.70 & 7.71 & 4.41 & 15.75 & \\
C-AOEw & 45.03 & 12.90 & 15.29 & 7.25 & 4.83 & 17.71 & \\
C-AOEa & 47.12 & 10.78 & 14.83 & 7.41 & 5.20 & 14.66 & \\
C-AOEwU & 47.86 & 9.65 & 14.95 & 7.47 & 5.15 & 14.91 & \\
C-AOEaU & 50.54 & 10.27 & 13.27 & 6.84 & 4.86 & 13.73 & \\
\hline C-BE & 41.18 & 10.48 & 13.61 & 10.16 & 6.03 & 18.54 & \\
C-BEw & 45.96 & 10.06 & 14.89 & 8.83 & 5.10 & 15.15 & \\
C-BEa & 43.76 & 13.30 & 9.95 & 6.05 & 4.23 & 19.91 & 2.80 \\
C-BEwU & 46.92 & 10.24 & 14.53 & 8.34 & 4.95 & 15.02 & \\
C-BEaU & 49.90 & 9.48 & 14.15 & 7.92 & 4.69 & 13.87 & \\
\hline
\end{tabular}

$284.8 \mathrm{eV}$ - C-C in graphitic carbon

$285.6 \mathrm{eV}-\mathrm{C}-(\mathrm{O}, \mathrm{N}, \mathrm{S}, \mathrm{H})$ in phenolic, alcoholic, etheric

$286.5 \mathrm{eV}-\mathrm{C}-\mathrm{N}$ in carbon-nitrogen structures and $-\mathrm{CH}_{2}-$ of PVDF

$287.5 \mathrm{eV}-\mathrm{C}=\mathrm{O}$ in carbonyl or quinone

$288.7 \mathrm{eV}-\mathrm{O}-\mathrm{C}=\mathrm{O}$ in carboxyl or ester

$290.7 \mathrm{eV}-\mathrm{C}-\mathrm{F}$ in polyvinylidene fluoride

$293.5 \mathrm{eV}-\mathrm{C}-\mathrm{F}$ in aromatic ring 
Table S3. The results of deconvolution of O 1 s core energy level and their binding energy.

\begin{tabular}{lcccc}
\hline Sample & $531.3 \mathrm{eV}$ & $533.3 \mathrm{eV}$ & $534.5 \mathrm{eV}$ & $536.2 \mathrm{eV}$ \\
\hline C-AOE & 43.80 & 48.63 & 7.56 & \\
C-AOEw & 35.44 & 57.54 & 7.02 & \\
C-AOEa & 40.96 & 52.61 & 6.43 & \\
C-AOEwU & 39.91 & 56.09 & 4.00 & \\
C-AOEaU & 41.54 & 53.12 & 5.35 & \\
\hline C-BE & 33.02 & 33.16 & 21.30 & 12.53 \\
C-BEw & 28.02 & 55.26 & 16.72 & \\
C-BEa & 30.86 & 53.15 & 15.99 & \\
C-BEwU & 32.06 & 53.16 & 14.79 & \\
C-BEaU & 33.10 & 53.74 & 13.16 & \\
\hline
\end{tabular}

$531.3 \mathrm{eV}-\mathrm{C}=\mathrm{O}$ in carbonyl, quinone or sulfoxides/ sulfones

$533.3 \mathrm{eV}$ - C-Oin phenol/epoxy, ether or thioethers/sulfonic

$534.5 \mathrm{eV}$ - -O- in carboxyl, water or chemisorbed oxygen species

$536.2 \mathrm{eV}$ - adsorbed water or oxygen, $\mathrm{C}=\mathrm{O}$ (occluded $\mathrm{CO}$ or $\mathrm{CO}_{2}$ ) 
Table S4. The results of deconvolution of $\mathrm{N} 1 \mathrm{~s}$ core energy level and their binding energy.

\begin{tabular}{lcccc}
\hline Sample & $398.3 \mathrm{eV}$ & $399.9 \mathrm{eV}$ & $401.4 \mathrm{eV}$ & $403.5 \mathrm{eV}$ \\
\hline C-AOE & 16.92 & 63.10 & 17.21 & 2.77 \\
C-AOEw & 15.82 & 56.57 & 22.10 & 5.51 \\
C-AOEa & 15.59 & 65.77 & 14.28 & 4.37 \\
C-AOEwU & 19.22 & 53.67 & 19.39 & 7.71 \\
C-AOEaU & 18.54 & 52.86 & 19.57 & 9.03 \\
\hline C-BE & 16.56 & 48.84 & 24.90 & 6.69 \\
C-BEw & 15.92 & 46.79 & 26.18 & 11.11 \\
C-BEa & 20.58 & 55.79 & 22.36 & 1.27 \\
C-BEwU & 17.39 & 48.17 & 26.71 & 7.73 \\
C-BEaU & 17.89 & 50.96 & 22.96 & 8.19 \\
\hline
\end{tabular}

$398.3 \mathrm{eV}-\mathrm{N}-6$ in pyridine

$399.9 \mathrm{eV}-\mathrm{N}-5$ in pyrrolic/pyridone and azo nitrogen

$401.4 \mathrm{eV}-\mathrm{N}-\mathrm{Q}$ in quaternary and might be also from protonated amines

$403.5 \mathrm{eV}-\mathrm{N}-\mathrm{X}$ in pyridine-N-oxide 
Table S5. The results of deconvolution of S 2p core energy level and their binding energy.

\begin{tabular}{lccccc}
\hline Sample & $163.5 \mathrm{eV}$ & $164.7 \mathrm{eV}$ & $167.2 \mathrm{eV}$ & $168.4 \mathrm{eV}$ & $169.2 \mathrm{eV}$ \\
\hline C-AOE & 90.24 & & 6.69 & 3.15 & \\
C-AOEw & 91.28 & & 1.14 & 8.05 & \\
C-AOEa & 59.01 & 6.35 & 10.78 & 15.90 & 7.95 \\
C-AOEwU & 47.60 & 14.05 & 9.45 & 12.41 & 6.50 \\
C-AOEaU & 60.31 & 10.95 & 6.31 & 13.56 & 8.86 \\
C-BE & 41.4 & 8.00 & 26.67 & 16.62 & 8.38 \\
C-BEw & 40.53 & 10.11 & 19.05 & 22.34 & 9.08 \\
C-BEa & 37.33 & 9.92 & 24.21 & 19.02 & 9.51 \\
C-BEwU & 41.31 & 5.66 & 26.70 & 16.08 & 10.25 \\
C-BEaU & 42.85 & 4.69 & 21.12 & 24.35 & 10.78 \\
\hline
\end{tabular}

$163.5 \mathrm{eV}$ - R-S-S- in thiol, bisulfides configuration $164.7 \mathrm{eV}-\mathrm{C}-\mathrm{S}-\mathrm{C} / \mathrm{R}-\mathrm{S}_{2}-\mathrm{OR}$ in sulfides and thioethers $167.2 \mathrm{eV}-\mathrm{R}_{2}-\mathrm{S}=\mathrm{O} / \mathrm{R}-\mathrm{SO}_{2}-\mathrm{R}$ in sulfoxides, sulfones $168.4 \mathrm{eV}-\mathrm{R}-\mathrm{SO}_{3} \mathrm{H} / \mathrm{SO}_{4}{ }^{2-}$ in sulfonic acids/sulphate $169.2 \mathrm{eV}-\mathrm{RO}_{2}-\mathrm{S}-\mathrm{S}-\mathrm{R}$ or $\mathrm{R}-\mathrm{SO}_{3} \mathrm{H}$ in sulfonic acids 


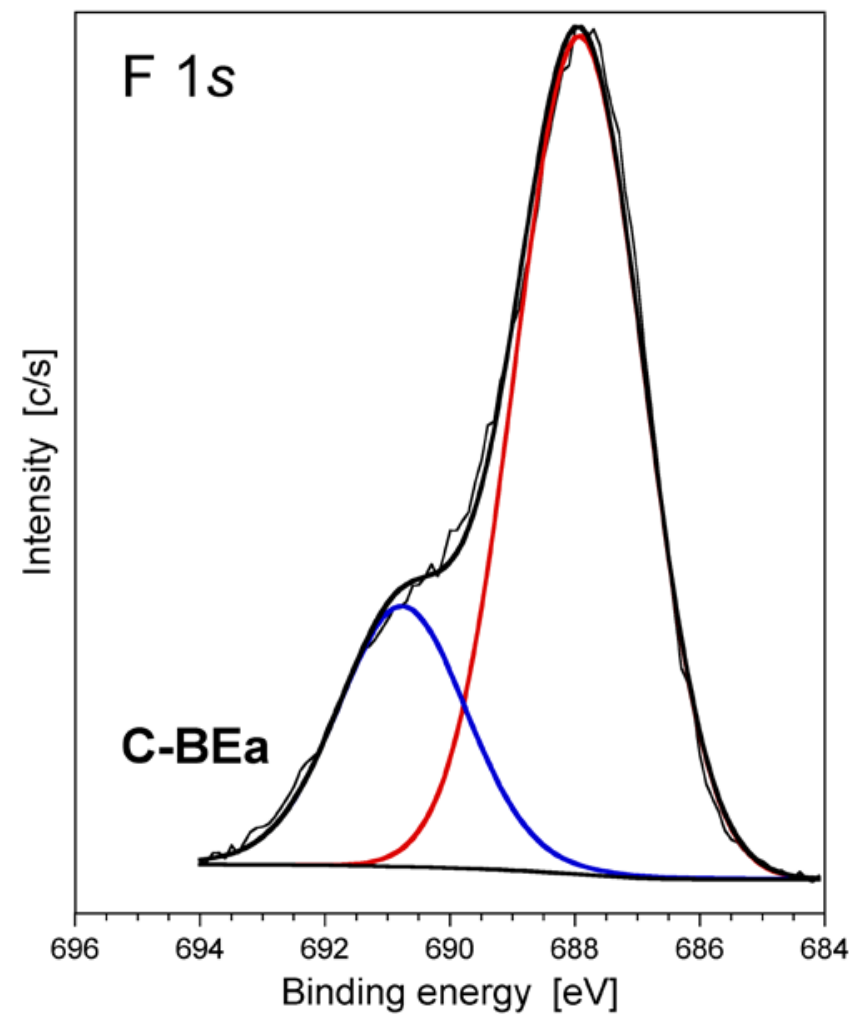

Figure S4. F 1s core energy levels for the non-oxidized carbon after wetting in sulfuric acid (CBEa). 

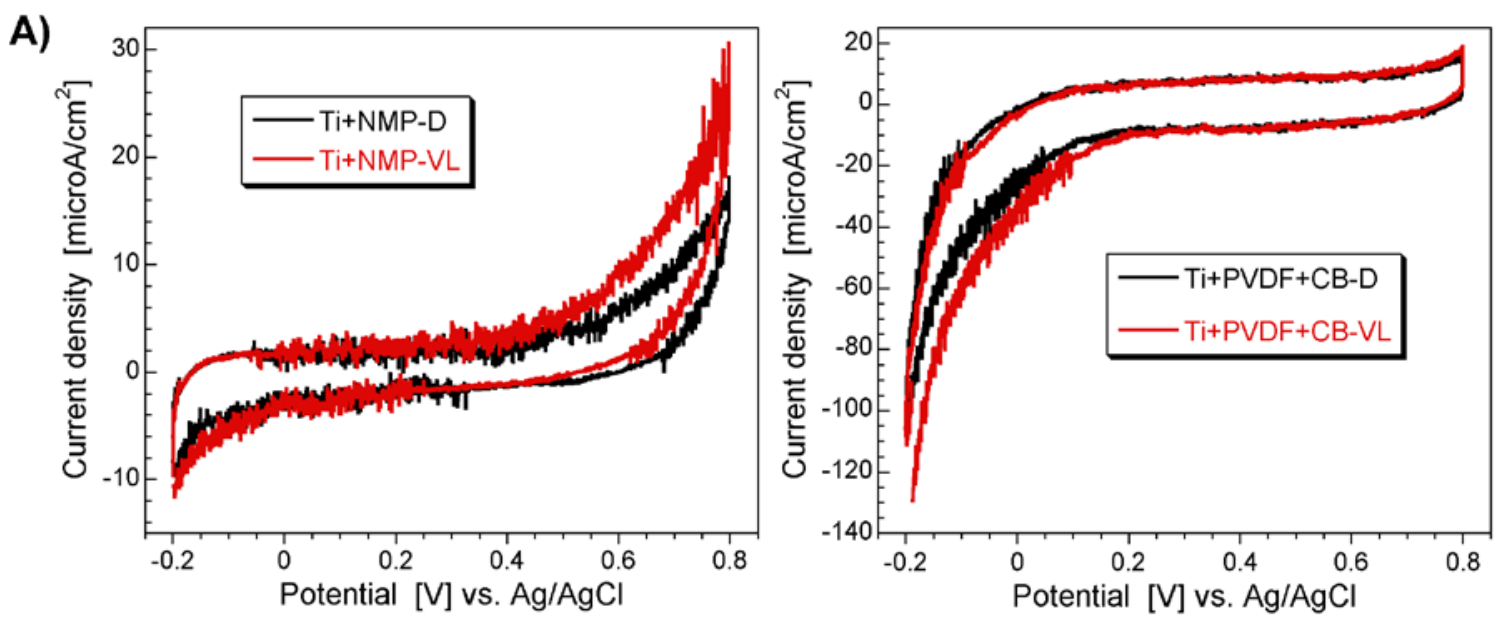

B)

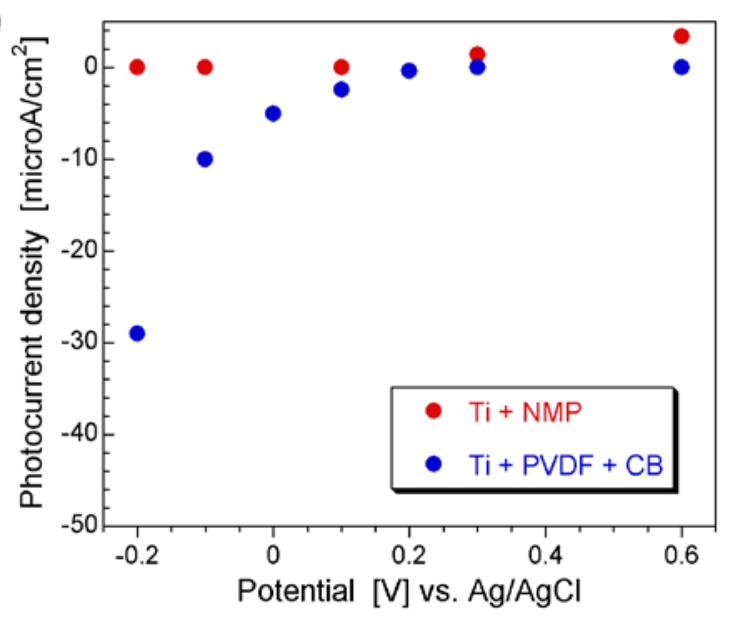

Figure S5. A) Cyclic voltammetry and B) Photocurrent response at various bias potentials for the Ti foil coated with N-methyl-2-pyrrolidone (NMP) and Ti foil pasted with $10 \mathrm{wt}$. \% binder (PVDF) and 90 wt. \% carbon black (CB) in dark - D and under visible light - VL exposure. 